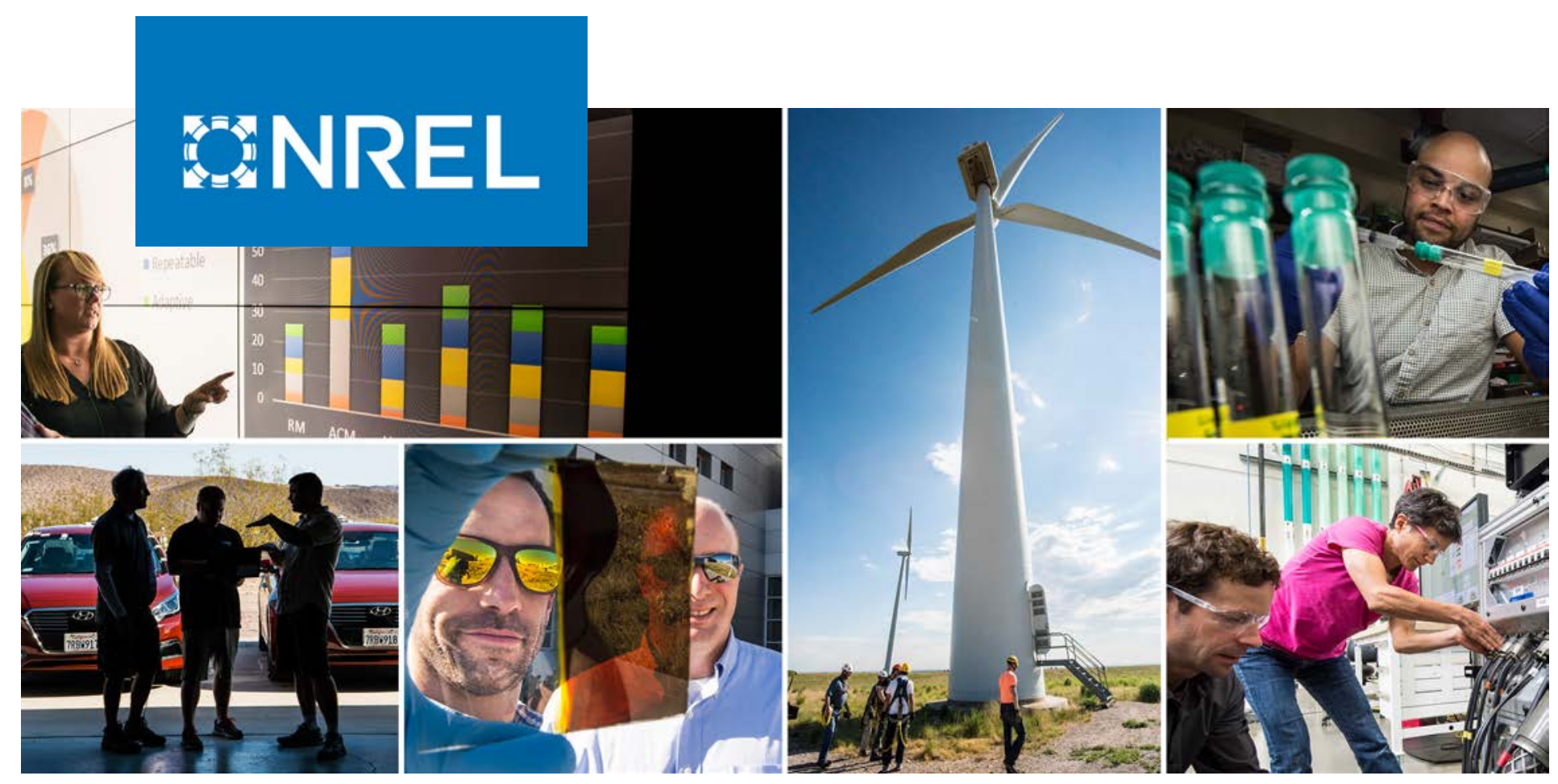

\title{
California Time-of-Use (TOU) Transition: Effects on Distributed Wind and Solar Economic Potential
}

Ashwin Ramdas, Kevin McCabe, Paritosh Das, and Benjamin Sigrin

National Renewable Energy Laboratory

NREL is a national laboratory of the U.S. Department of Energy

Office of Energy Efficiency \& Renewable Energy

Operated by the Alliance for Sustainable Energy, LLC

This report is available at no cost from the National Renewable Energy Laboratory (NREL) at www.nrel.gov/publications.

\section{Technical Report}

NREL/TP-6A20-73147

April 2019 


\title{
GNREL
}

\section{California Time-of-Use (TOU) Transition: Effects on Distributed Wind and Solar Economic Potential}

\author{
Ashwin Ramdas, Kevin McCabe, Paritosh Das, \\ and Benjamin Sigrin
}

National Renewable Energy Laboratory

\section{Suggested Citation}

Ramdas, Ashwin, Kevin McCabe, Paritosh Das, and Benjamin Sigrin. 2019. California

Time-of-Use (TOU) Transition: Effects on Distributed Wind and Solar Economic Potential.

Golden, CO: National Renewable Energy Laboratory. NREL/TP-6A20-73147.

https://www.nrel.gov/docs/fy19osti/73147.

NREL is a national laboratory of the U.S. Department of Energy Office of Energy Efficiency \& Renewable Energy Operated by the Alliance for Sustainable Energy, LLC

This report is available at no cost from the National Renewable Energy Laboratory (NREL) at www.nrel.gov/publications.

Contract No. DE-AC36-08GO28308
Technical Report

NREL/TP-6A20-73147

April 2019

National Renewable Energy Laboratory 15013 Denver West Parkway Golden, CO 80401

303-275-3000 • www.nrel.gov 


\section{NOTICE}

This work was authored by the National Renewable Energy Laboratory, operated by Alliance for Sustainable Energy, LLC, for the U.S. Department of Energy (DOE) under Contract No. DE-AC36-08G028308. Funding provided by U.S. Department of Energy Office of Energy Efficiency and Renewable Energy Wind and Water Power Program. The views expressed herein do not necessarily represent the views of the DOE or the U.S. Government.

This report is available at no cost from the National Renewable Energy Laboratory (NREL) at www.nrel.gov/publications.

U.S. Department of Energy (DOE) reports produced after 1991 and a growing number of pre-1991 documents are available free via www.OSTI.gov.

Cover Photos by Dennis Schroeder: (clockwise, left to right) NREL 51934, NREL 45897, NREL 42160, NREL 45891, NREL 48097, NREL 46526.

NREL prints on paper that contains recycled content. 


\section{Acknowledgments}

This work was supported by the U.S. Department of Energy (DOE) Wind Energy Technology Office under Contract No. DEAC36-08GO28308 with the National Renewable Energy Laboratory (NREL). The authors thank Ian Baring-Gould, Bret Barker, Michael Bergey, Patrick Gilman, Juliet Homer, Jennie Jorgensen, Jereme Kent, Eric Lantz, and Alice Orrell for their thoughtful reviews and other contributions. Opinions represented in this report are the authors' own and do not reflect the view of the U.S. Department of Energy or the U.S. government. Any remaining errors or omissions are the sole responsibility of the authors. 


\section{List of Acronyms and Abbreviations}

$\begin{array}{ll}\text { ATB } & \text { Annual Technology Baseline } \\ \text { BANC } & \text { Balancing Authority of Northern California } \\ \text { CAPEX } & \text { capital expenditure } \\ \text { CEC } & \text { California Energy Commission } \\ \text { CIPB } & \text { Pacific Gas \& Electric Bay Area Balancing Authority } \\ \text { CIPV } & \text { Pacific Gas \& Electric Valley Area Balancing Authority } \\ \text { CISC } & \text { Southern California Edison Balancing Authority } \\ \text { CISD } & \text { San Diego Gas \& Electric Balancing Authority } \\ \text { CPUC } & \text { California Public Utility Commission } \\ \text { CSBOE } & \text { California State Board of Equalization } \\ \text { DER } & \text { distributed energy resources } \\ \text { dGen } & \text { Distributed Generation Market Demand } \\ \text { DNI } & \text { direct normal solar irradiance } \\ \text { DOE } & \text { U.S. Department of Energy } \\ \text { DPV } & \text { distributed solar photovoltaics } \\ \text { DW } & \text { distributed wind } \\ \text { GW } & \text { gigawatt } \\ \text { GWDC } & \text { gigawatt-direct current } \\ \text { IID } & \text { Imperial Irrigation District } \\ \text { kW } & \text { kilowatt } \\ \text { LBNL } & \text { Lawrence Berkeley National Laboratory } \\ \text { LDWP } & \text { Los Angeles Department of Water \& Power } \\ \text { MW } & \text { megawatt } \\ \text { MWDC } & \text { megawatt-direct current } \\ \text { NPV } & \text { net present value } \\ \text { NREL } & \text { National Renewable Energy Laboratory } \\ \text { REPLICA } & \text { Rooftop Energy Potential of Low Income Communities in America } \\ \text { SGIP } & \text { Self-Generation Incentive Program } \\ \text { TRG } & \text { techno-resource group } \\ \text { TOU } & \text { time of use } \\ \text { URDB } & \text { Utility Rate Database } \\ & \\ & \end{array}$




\section{Executive Summary}

Time-of-use (TOU) retail energy rates price electricity differently by the time of day, thereby communicating to consumers the costs of supplying electricity throughout the day. As a successor to volumetric rates, TOU rates are part of a broader movement to modernize demandside loads. In 2015, the California Public Utility Commission announced reforms to better align costs of electricity supply and demand. Most prominently, Decision D.15.07-001 initiated a transition to TOU tariffs for all residential customers, to begin implementation in 2019. An impact of the transition is the change in the value of distributed wind and solar generation, based on the correlation of each technology's generation with retail prices. In part, this relative change in value under TOU could be considered an implication of the "duck curve"- as solar penetration in California increases, it depresses the price of midday generation and increases prices during afternoon peak load.

This study evaluates the impact of the pending enactment of the California TOU mandate on the economic attractiveness of behind-the-meter distributed wind and solar systems, both in isolation and after accounting for inter-technology competition. We assess attractiveness through "economic potential," a metric we define as the amount of generation capacity, both existing and hypothetical, that exceeds a specified rate of return $(5.4 \%)$ and therefore would be economic to construct. In addition, we identify cost improvements needed for a robust (i.e., 1-gigawatt [GW]) distributed wind market and the specific counties and sectors with substantial wind and solar economic potential. To assess the TOU impact, we compiled all non-TOU and (opt-in) TOU rates currently offered by utilities, with the presumption that the to-be-announced rates will be comparable to today's opt-in rates. The pre-TOU and TOU rates are also normalized under the presumption that the transition will result in the same amount of revenue collected, or alternatively that the average cost of electricity to consumers remains constant.

\section{Implications of TOU Transition on Distributed Wind and Solar Economic Potential}

Over the scenarios considered, model results indicate there are realistic pathways to reaching a 1-GW distributed wind market in California (Figure ES-1, next page), though solar economic potential was found to be substantially larger than that of wind potential. Distributed wind's capacity factor does not appear to be strongly correlated to the periods of peak electricity prices as set by utility's TOU periods. Because of this disassociation and nuances in the billing of tiered electricity, the transition to TOU is projected to moderately decrease distributed wind economic potential and increase that of distributed solar. However, a limitation of this analysis is that it does not factor in the change in rate values as California works toward its goal of $100 \%$ renewables. As variable renewable energy penetration increases to meet this goal, our results suggest that wind generation will become increasingly correlated to periods of peak electricity prices. Increased variable renewable penetration, especially of solar, is likely to shift periods of higher electricity demand to later in the evening, and any periodic adjustments in TOU periods to reflect these new periods of demand will positively affect the value of wind generation more than the value of solar generation.

In addition to capital costs and retail electricity prices, two techno-economic factors were found to have a significant impact on distributed wind economic potential: the assumed statutory expiration of state (i.e., California) and federal incentives, and gradual improvements in solar panel efficiency. 

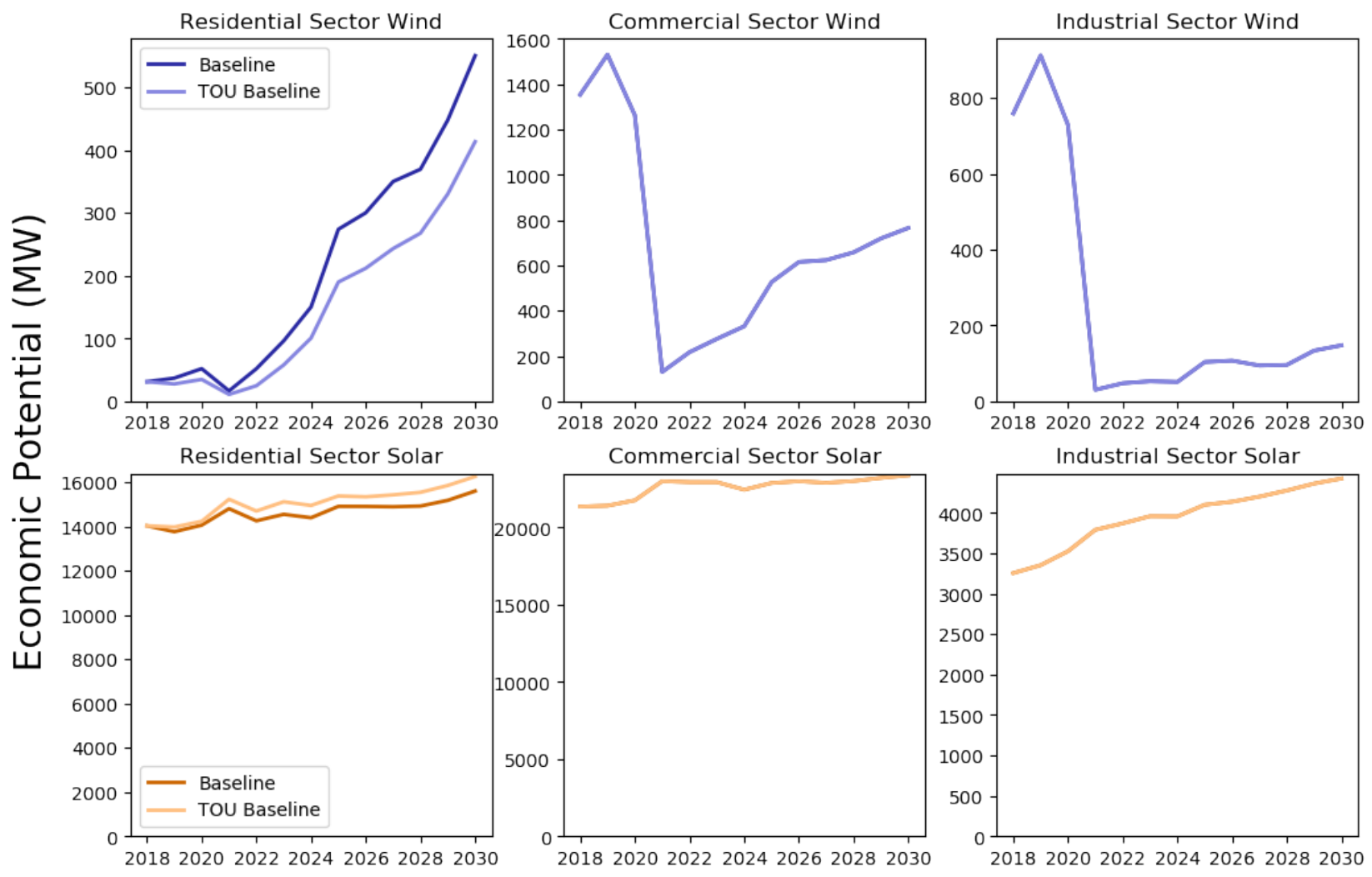

Figure ES-1. Economic potential of distributed wind (top row) and solar (bottom row) by sector

Commercial and Industrial sectors are on mandatory TOU rates prior to 2019.

\section{Sensitivity of Distributed Wind Economic Potential to Capital Cost Reductions}

High distributed wind capital costs are a significant barrier to large-scale adoption, and they impact economic potential more than the transition to TOU rates, according to our model. To understand potential returns to government research, development, and demonstration expenditures, we explore the sensitivity of capital cost reductions on distributed wind economic potential (Figure ES-2, next page). We find that distributed wind economic potential increases substantially in 2020 for capital costs below $\$ 3 / \mathrm{W}$ - particularly for residential- and commercialscale turbines; capital costs must fall below $\$ 2 / \mathrm{W}$ in 2030 to support a significant increase in economic potential, in large part due to the expected continued cost reductions in solar. We identified an upper limit to the state's behind-the-meter distributed wind economic potential at approximately $5 \mathrm{GW}$ that is due to inherent turbine siting challenges as well as the spatial distribution and quantities of load. 


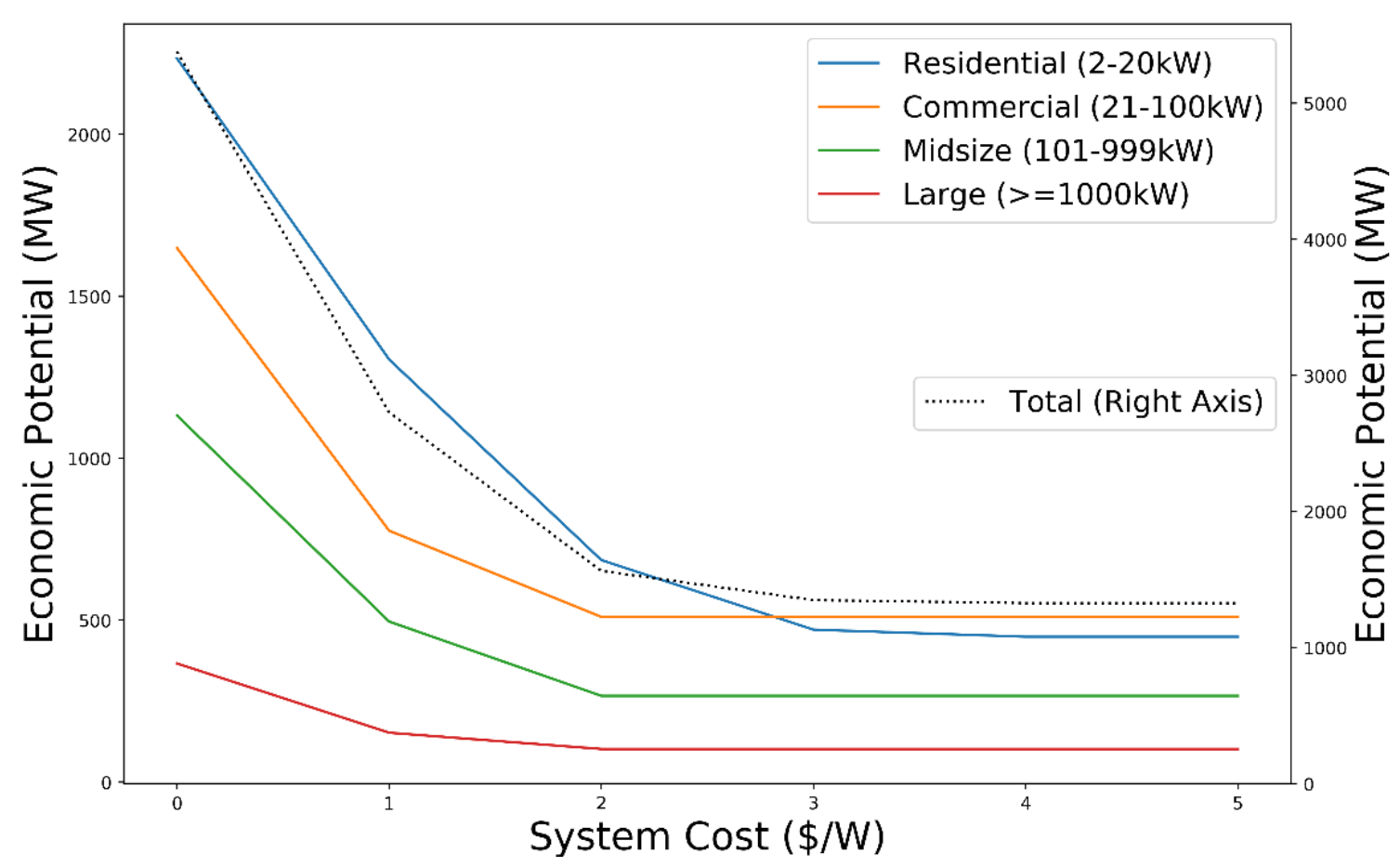

Figure ES-2. Economic potential of distributed wind versus system cost in 2030, by turbine class (left axis) and in aggregate (right axis)

\section{Geographic Trends in DER Economic Potential}

Several geospatial factors affect the geographic distribution of economic potential. Under our TOU Baseline scenario, which assumes reference capital costs and that TOU rates are in effect, the regions of California that exhibit the most economic potential in 2030 were Southern California, namely San Bernardino County and Los Angeles County, and counties including and surrounding San Joaquin County in central California. Solar economic potential is also highest in Southern California, with the most potential being projected in Los Angeles County. At costs of $\$ 1 / \mathrm{W}$, Los Angeles, San Bernardino, and Riverside counties could see noteworthy increases in their distributed wind economic potential.

Overall, California exhibits over $1 \mathrm{GW}$ of economic potential for distributed wind by 2030 , even with the moderate decrease in potential under TOU. This potential is represented mostly by Southern California, which sees the most notable increase in economic viability as capital expenditure prices decline. Figure ES-3 and ES-4 show the geographic distribution of economic potential as well as underlying data that feeds into the economic potential estimations.

\section{Limitations of This Analysis}

Our analysis investigates the economic viability of distributed wind and distributed solar; we do not attempt to project deployment or adoption. Though we attempt to model the value of distributed wind and distributed solar generation as variable renewable energy penetration increases, we neither incorporate the technical limitations of variable renewable energy nor model energy storage in this analysis. Additionally, as mentioned above, our analysis relies on the currently available TOU rates and presumes the eventual default TOU rates will be similar. 


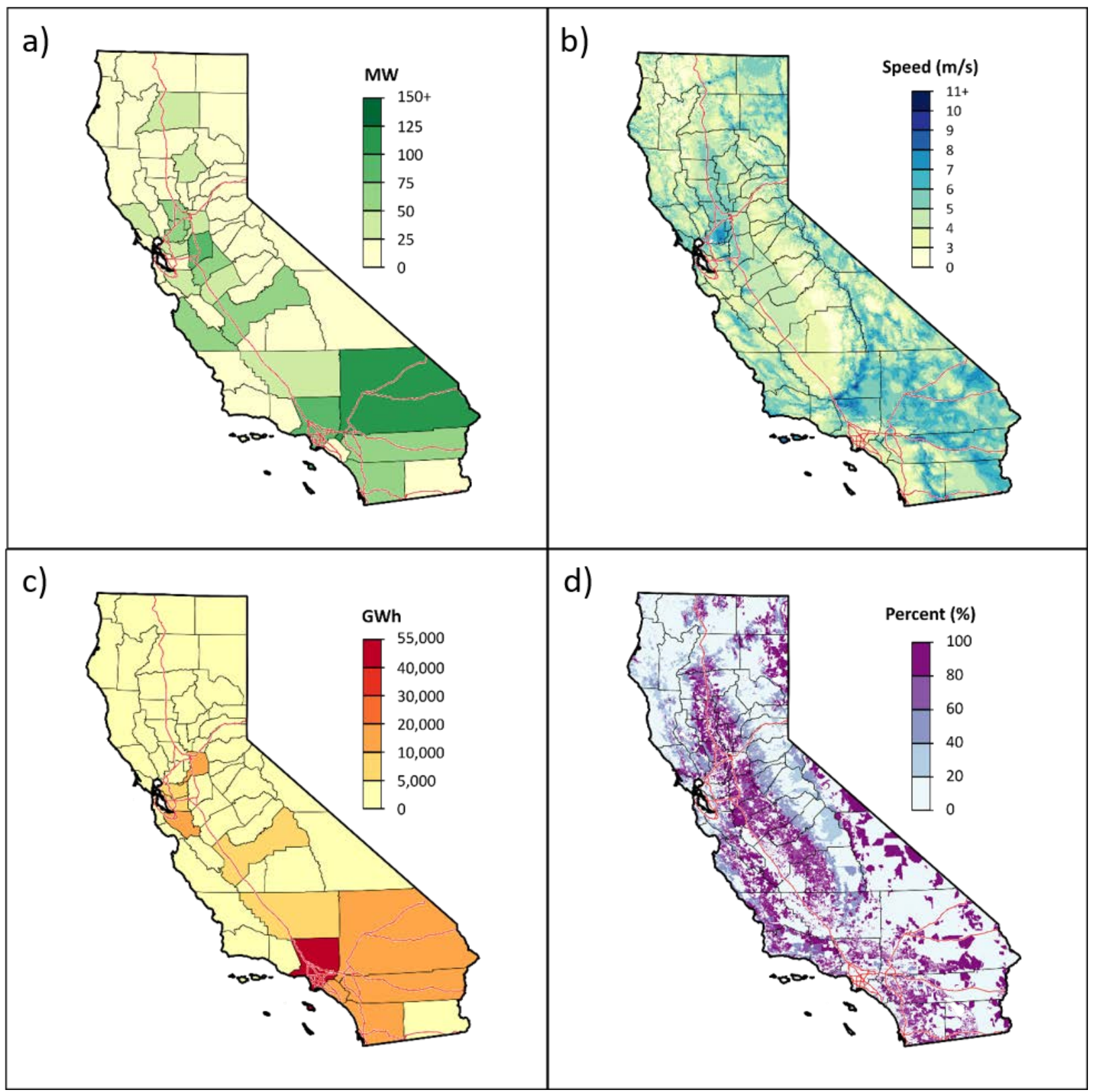

Figure ES-3. County maps of California highlighting the following statistics: (a) total (all sectors and turbine classes) distributed wind economic potential (megawatts [MW]) in 2030 for the TOU Baseline scenario, (b) wind resource at $80-\mathrm{m}$ hub height, (c) annual electricity consumption, and (d) distributed wind siting availability 


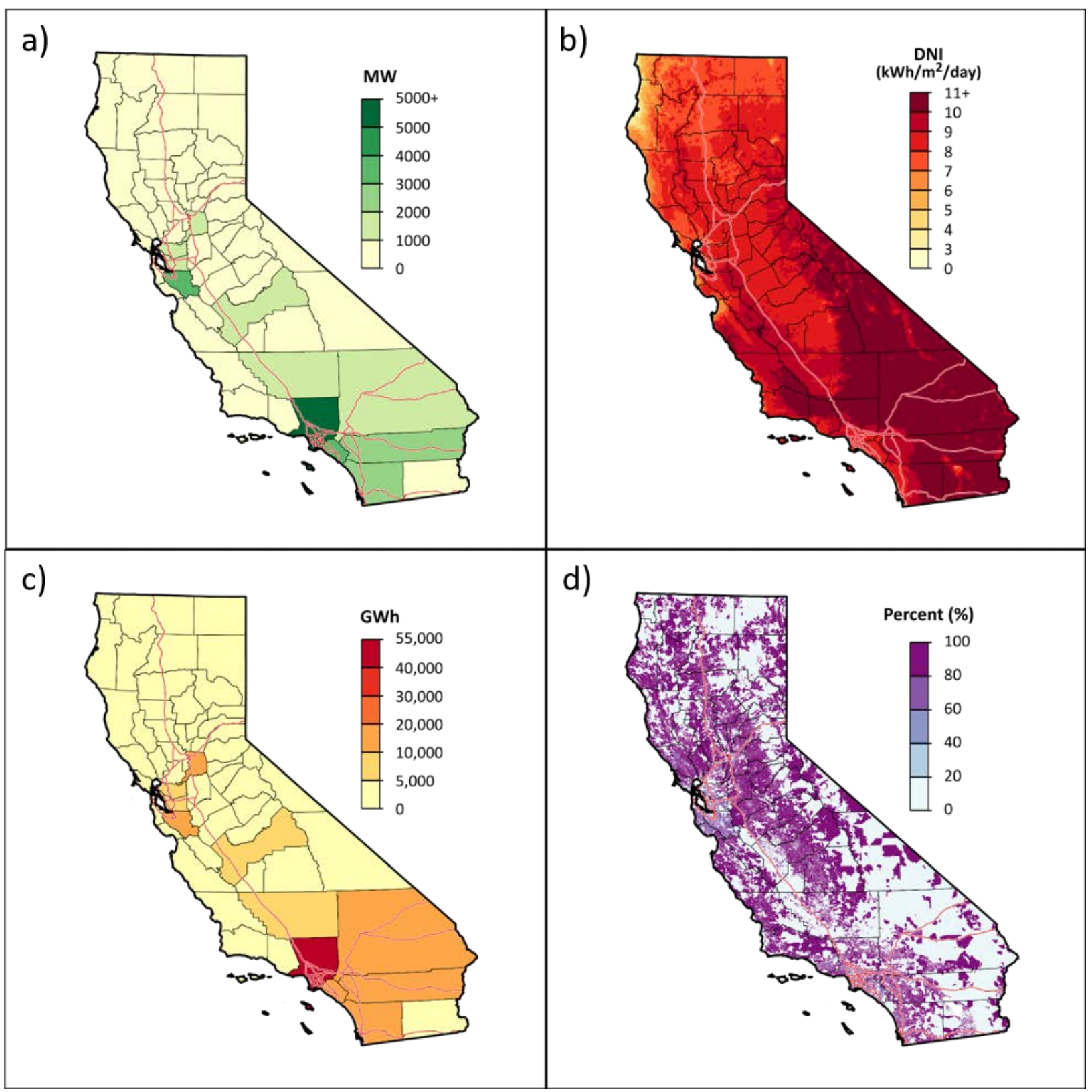

Figure ES-4. County maps of California highlighting the following statistics: (a) total (all sectors) distributed solar economic potential (MW) in 2030 for the TOU Baseline scenario, (b) solar resource strength, (c) annual electricity consumption, (d) and distributed solar siting availability

Note the difference in scale between the distributed solar and distributed wind economic potential map. 
Note

The Time-of-Use (TOU) peak periods used in this analysis for Southern California Edison (SCE) were based off of the optional residential TOU rates and the mandatory commercial and industrial TOU rates offered as of September 12, 2018. As of April 12, 2019, SCE's two new residential TOU rates shifted the on-peak period from 2-8 p.m. to 4-9 p.m. or 5-8 p.m. As of March 1, 2019, SCE's new commercial and industrial TOU rates shifted the on-peak period from 12-6 p.m. to 4-9 p.m. This analysis is unable to assess the impact of the revised tariffs on the economic potential of distributed wind and solar. The TOU peak periods for the Pacific Gas \& Electric (PG\&E) and San Diego Gas \& Electric (SDG\&E) rates used in this analysis are aligned with the currently offered TOU rates by these utilities. 


\section{Table of Contents}

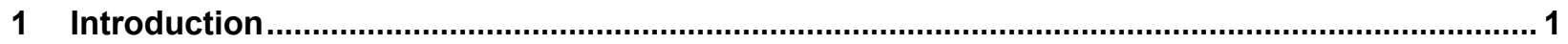

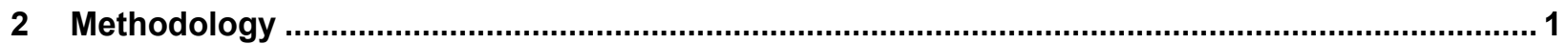

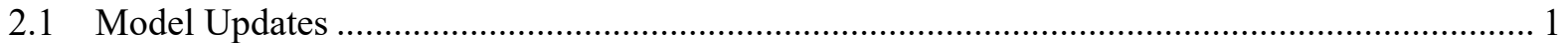

2.1.1 Implementation of New Data Sets........................................................................... 1

2.1.2 Representation of California Time-of-Use Mandate ...................................................... 2

2.1.3 Competition Among Distributed Generation Technologies........................................... 3

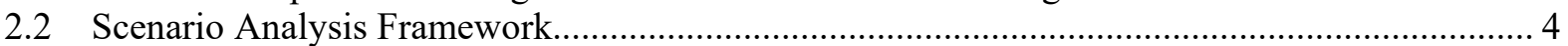

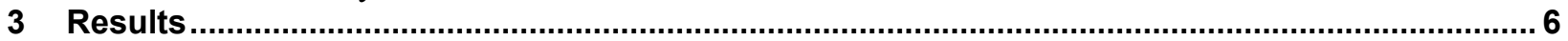

3.1 Implications of TOU Transition ........................................................................................ 6

3.1.1 Economic Potential of Distributed Wind and Distributed Solar ...................................... 6

3.1.2 Examination of Distributed Wind Economic Potential Decline Under TOU ................. 10

3.2 Effect of Cost on Distributed Wind Potential ………………………………………............ 14

3.2.1 Potential of Distributed Wind in a Noncompetitive and Competitive Environment...... 15

3.2.2 Potential of Distributed Solar in a Noncompetitive and Competitive Environment ...... 17

3.2.3 Sensitivity of Distributed Wind Potential to Opportunistic Cost Improvements ........... 19

3.3 The Value of Distributed Wind and Distributed Solar Generation with Increased Variable

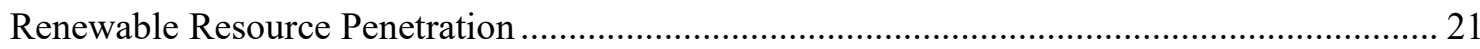

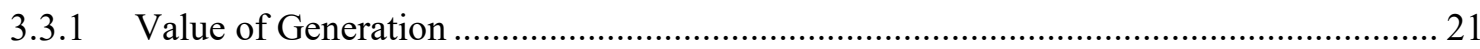

3.3.2 Change in Value of Generation........................................................................... 22

3.4 Geospatial Trends in Distributed Generation Potential........................................................ 23

3.4.1 Economic Potential ...................................................................................... 24

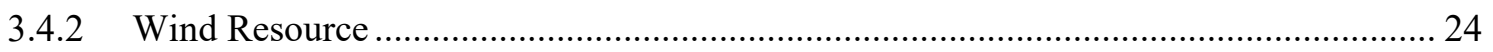

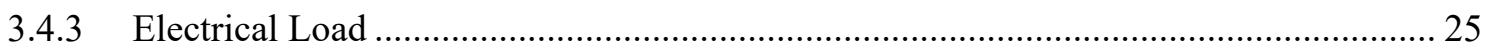

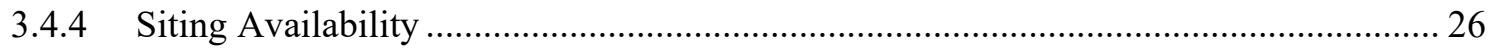

3.4.5 Effects of Capital Cost Reductions on Distributed Generation Potential....................... 28

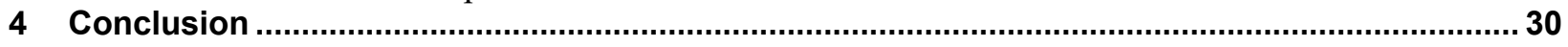

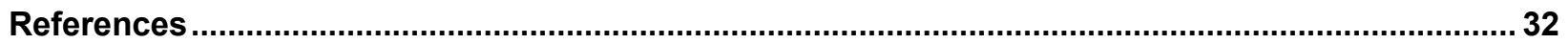

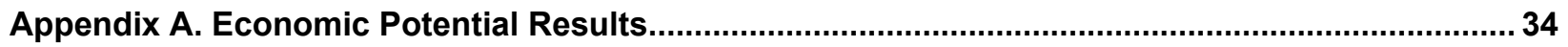

Appendix B. Distributed Wind Capital Costs ............................................................................ 35

Appendix C. Economic Potential Results........................................................................ 37

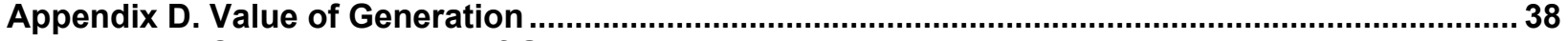

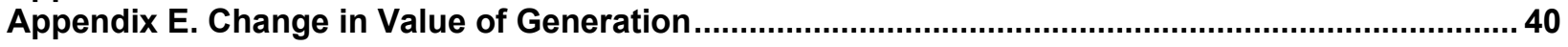




\section{List of Figures}

Figure ES-1. Economic potential of distributed wind (top row) and solar (bottom row) by sector.............vi Figure ES-2. Economic potential of distributed wind versus system cost in 2030, by turbine class (left axis) and in aggregate (right axis) vii

Figure ES-3. County maps of California highlighting the following statistics: (a) total (all sectors and turbine classes) distributed wind economic potential (megawatts [MW]) in 2030 for the TOU Baseline scenario, (b) wind resource at 80-m hub height, (c) annual electricity consumption, and (d) distributed wind siting availability viii

Figure ES-4. County maps of California highlighting the following statistics: (a) total (all sectors) distributed solar economic potential (MW) in 2030 for the TOU Baseline scenario, (b) solar resource strength, (c) annual electricity consumption, (d) and distributed solar siting availability..... ix

Figure 1. Effect of TOU mandate on economic potential of distributed wind........................................ 7

Figure 2. Effect of TOU mandate on economic potential of distributed solar........................................... 7

Figure 3. Breakdown of distributed wind economic potential (left) and number of projects (right) by

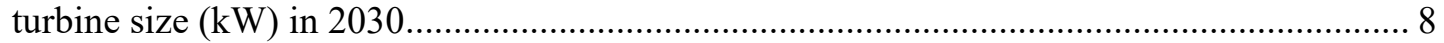

Figure 4. Economic potential of distributed wind (top row) and distributed solar (bottom row) by sector 10 Figure 5. A sample load profile from a summer weekday for a Southern California Edison customer in San Bernardino overlaid with average summer generation in San Bernardino with a 10-kW wind system.

Figure 6. Overlay of net electricity demand (left axis), hourly rates for a wind system under tiered rates (right axis), and no wind system under tiered rates (right axis) ......................................... 12

Figure 7. Comparison of cumulative bills for a wind system under TOU and a wind system under a tiered rate structure.

Figure 8. Overlay of residential TOU tiers with summer (left) and winter (right) capacity factor profiles 14

Figure 9. Economic potential of distributed wind in the TOU Baseline and TOU High Cost Wind scenarios with no solar competition.

Figure 10. Economic potential of distributed wind in the TOU Baseline and TOU High Cost Wind scenarios with solar competition.

Figure 11. Economic potential of distributed solar in the TOU High Cost Solar, TOU Baseline, and TOU Low Cost Solar scenarios with no wind competition.

Figure 12. Economic potential of distributed solar in the TOU High Cost Solar, TOU Baseline, and TOU Low Cost Solar scenarios with wind competition....

Figure 13. Economic potential of distributed wind versus system cost in 2020 by turbine class (left axis) and compiled as a total (right axis).

Figure 14. Economic potential of distributed wind versus system cost in 2030 by turbine class (left axis) and compiled as a total (right axis) ......................................................................... 20

Figure 15. Difference between the value of wind generation and the value of solar generation, by county

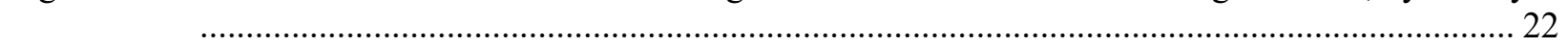

Figure 16. Difference between the percent change in generation value from 2020 of solar and wind....... 23

Figure 17. Total (all sectors and turbine classes) economic potential (MW) in 2030 for the TOU Baseline

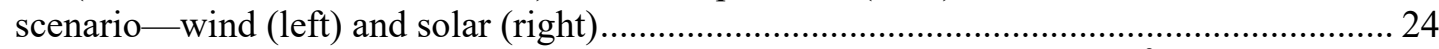

Figure 18. Average wind speed $(\mathrm{m} / \mathrm{s})$ at 80 -meter hub height in (left) and DNI $\left(\mathrm{kWh} / \mathrm{m}^{2} /\right.$ day) (right) ..... 25

Figure 19. Average wind speed $(\mathrm{m} / \mathrm{s})$ at 30 -meter hub height ......................................................... 25

Figure 20. Projected annual electricity consumption (GWh) for all (residential, commercial,

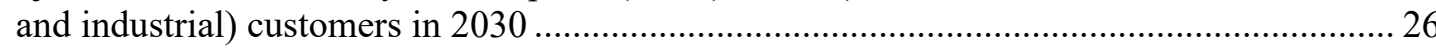

Figure 21. Favorability for siting availability for wind (left) and solar (right) ...................................2 27

Figure 22. Map of tract-level solar siting availability for the southern and eastern Bay Area .................. 28

Figure 23. Change in economic potential relative to the TOU Baseline scenario results for the TOU High Cost Solar scenario (left), \$1/W scenario (middle), and \$0/W scenario (right)..................... 29 


\section{List of Tables}

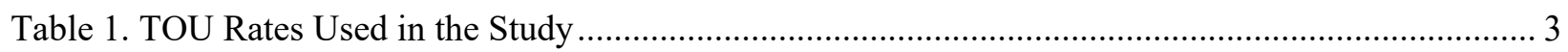

Table 2. Distributed Wind Capital Cost Scenarios ........................................................................... 5

Table 3. Full Scenario Matrix, Including Scenario Names, Wind and Solar Cost Schedules, and the Rate

Case Used in Each Scenario.............................................................................................. 5

Table 4. CAPEX for Distributed Wind Under the TOU Baseline and TOU High Cost Scenarios in 203015

Table 5. Projected Installed Capacity Upon Which the Hourly Wholesale Electricity Prices are Based ... 21

Table A-1. Economic Potential Results by Technology and Scenario in Megawatts ............................... 34

Table B-1. Distributed Wind Capital Costs by Cost Scenario in $\$ / k W D o l l a r s$ per Kilowatt for the Baseline

Scenario

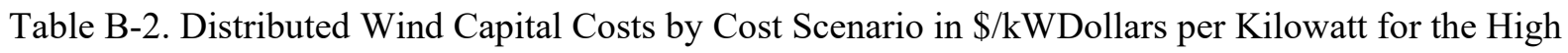

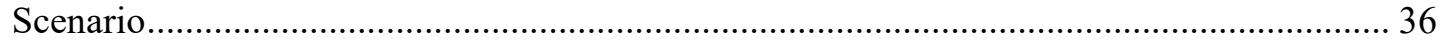

Table C-1. Economic Potential Results by Turbine Class of Capital Cost Sensitivity Analysis in 2020 ... 37

Table C-2. Economic Potential Results by Turbine Class of Capital Cost Sensitivity Analysis in 2030 ... 37

Table D-1. Value of 10,000 kWh of Generation by Technology by Year 38

Table E-1. Change in Value of 10,000 kWh of Generation by Technology by Year 40 


\section{Introduction}

Costs of supplying electricity vary substantially by the time of day, location, and the portfolio of generation resources serving a system. However, the price signals that consumers (i.e., demand) are exposed to are typically different from the cost of generation (i.e., supply). Instead, most residential retail tariffs are structured around a desire for simplicity to the consumer and an assumption of low elasticity of demand. Several factors - particularly the rise of zero marginal cost solar and wind generation - motivate a realignment of the demand and supply price signals.

Starting with AB 327 in 2013 and continuing with Decision D.15.07-001 in 2015, the California Public Utility Commission initiated a series of regulations seeking to reform residential electricity rates to better align costs of electricity supply and demand. Most prominently, Decision D.15.07-001 initiated a transition to time-of-use (TOU) tariffs for residential customers, though it also instituted measures to consolidate residential electricity tiers and implemented a minimum electricity bill. Though the final TOU rates are not yet publicly available, they are expected to result in higher prices during periods of peak system demand (e.g., afternoons and evenings, particularly in the summer) and lower prices during off-peak hours when demand is lower. Notably, periods of peak demand coincide with hours of lower solar irradiance, so transition to TOU tariffs will not only affect how much California consumers pay for electricity throughout the day but also the value of distributed wind and solar generation.

This study seeks to understand the impact of the pending enactment of the TOU mandate on the economic attractiveness of behind-the-meter distributed wind and solar systems in California for residential, commercial, and industrial sectors. We assess attractiveness through the economic potential of distributed wind and solar, a metric of the amount of generation capacity - both existing and hypothetical — that exceeds a specified rate of return and therefore would be economic to construct. We define "economic potential" of distributed generation here as the amount of capacity that could be installed and achieve a positive net present value (NPV) using a 5.4\% weighted average cost of capital over its lifecycle, inclusive of capital and operation and maintenance costs, savings on retail electricity costs, applicable incentives, and tax implications. Using this definition, we project the cost competitiveness of distributed wind and solar through 2030 for each sector and by county with retail grid-sourced electricity under the TOU mandate as compared to a counterfactual scenario in which current residential rates are extended.

We use the NREL Distributed Generation Market Demand (dGen) model (Sigrin et al. 2016; Lantz et al. 2016), an agent-based model of distributed energy resources (DER) adoption to project the technical and economic potential of behind-the-meter distributed wind and solar in California. The dGen model simulates the resource, economics, siting, load, and policy conditions for thousands of potential distributed wind and solar sites across California. We use these methods and data to answer the following research questions:

- What are the implications of TOU retail tariffs in California for the economic competitiveness of behind-the-meter distributed wind and solar in 2030? A better alignment of retail prices with costs of wholesale generation, particularly with increased solar penetration, should influence the value of distributed generation, and thus the intertechnology financial attractiveness. 
- What level of cost and performance improvement would be needed for a robust California distributed wind market when accounting for distributed solar competition? Though California's high retail electricity prices and supportive DER policy both contribute to the viability of distributed wind, siting difficulties and historically high capital costs both challenge the maintenance of a dynamic distributed wind market. We examine the level of cost reduction needed for a "robust" 1-gigawatt-direct-current (GWDC) market and discuss its feasibility.

- In which regions and sectors of California are distributed wind already competitive with distributed solar? Which areas are the first to emerge as competitive? The emergence of new technologies depends on niches where the emerging technology provides superior value over the status quo. Specific counties, sectors, or end uses could provide such niches, and thus allow the distributed wind market to scale over time.

California has a rich history of policy actions influencing the economic viability of DERs. Here we summarize two macro trends: policies incentivizing the deployment of DERs and historical changes in retail electricity in the state.

Starting in 1997 with the implementation of the Emerging Renewables Program and other follow-on programs - including the Self-Generation Incentive Program (SGIP) and the California Solar Initiative-California has a long history of state-level support for DERs. The primary goal of these programs has been to develop a self-sustaining market for renewable energy in distributed generation applications (Go Solar n.d.). These include programs directed at single-family and multifamily buildings as well as low-income populations. The SGIP is still in effect statewide for distributed wind, and several incentives for solar are available at select utilities; for example, the statewide Single-Family Affordable Solar Homes rebate program is still active as of the time of publication.

Complementing these incentives, California's retail electricity prices are among the highest in the United States. Of note is the "tiered" structure of residential rates, where the increasing marginal cost of consumption disproportionately incentivizes the reduction of consumption for high-consumption households through distributed generation and energy efficiency. Rates are also structured to promote equity in the energy burden, where users in different climate regions are assigned a "baseline" daily consumption that ensures equal monthly energy costs across climate regions. Decision D.15.07-001 is expected to reduce the number of tiers and the variance of price between tiers, which would have a distributional influence on DER economics for different consumers.

By a combination of high retail prices and supportive policy, California leads the nation in deployment of DERs. Through September 2018, over 9,300 megawatts-direct current (MWDC) of residential and nonresidential solar had been deployed (Wood Mackenzie 2018). Despite these favorable conditions, distributed wind deployment in California remained at $70 \mathrm{MW}$ through 2017 (DOE 2018). Research has identified multiple additional barriers to distributed wind deployment, including siting challenges in urban areas (Lantz et al. 2016) and high capital and operation and maintenance costs (DOE 2018) that inhibit industry scale-up and cost reduction. Other factors include expensive permitting, a lack of property tax exclusions for distributed wind as distributed solar (CSBOE 2008), and differences in the availability of incentives for distributed wind and distributed solar. Also, McCabe et al. (2018) demonstrated that these factors 
are not spatially uniform and can result in conditions favorable to distributed wind development in targeted regions. As the penetration of distributed and utility-scale solar increases, grid integration issues are likely to come to the forefront; for example, the "duck curve" phenomenon (Denholm et al. 2015; Denholm, Clark, and O’Connell 2016) increases ramping requirements, shifts net peak load (and prices) later in the day, and increases curtailment during periods of excess variable generation. These phenomena could increase the value of distributed wind generation relative to that of distributed solar.

Results in this report are based on modeling and are subject to refinement. First, though the transition to TOU rates will begin in $2019,{ }^{1}$ the exact policy details were unavailable to the authors at the time of publication. Such details include definitions of the TOU periods and their electricity prices. Considering this uncertainty, we assume the enacted TOU rates will be comparable to the voluntary opt-in TOU tariffs already available today and that the TOU transition will be revenue-neutral (i.e., that the average cost of electricity pre-TOU and postTOU is constant). Second, following NREL practice, we assume all currently enacted policies will expire per their statutory authority. For instance, many of the state and federal policies modeled are currently scheduled to expire between 2020 and 2024, though in practice, they could be renewed or modified in other meaningful ways. Finally, this analysis is relatively static in that it does not consider future evolution of retail electricity rates in California, for example, as a result of increasing utility-scale renewable energy deployment. However, many studies (Darghouth et al. 2016; Denholm, Clark, and O'Connell 2016; Mills and Wiser 2012) have indicated that the increasing deployment of solar and wind generation will affect both the absolute cost of electricity and the timing of peak electricity price.

The remainder of the report is organized as follows. Section 2 details the methodology used, including model specification, the scenarios examined, and technology capital cost trajectories. Section 3 presents the results of the three research questions listed above, specifically, the projected implication of TOU transition on distributed wind and solar technical potential, how the potential varies by future capital cost assumptions, and analysis of the regions and sectors that are most favorable for distributed wind and solar. Finally, Section 4 provides a discussion of the results and our conclusions.

\footnotetext{
${ }^{1}$ Under Decision 18-05-011, roll out of mandatory TOU rates has been delayed until October 2020 for Pacific Gas
} and Electric and Southern California Edison customers. 


\section{Methodology}

As stated in the Introduction, we use the agent-based dGen model to project the technical and economic potential of behind-the-meter distributed wind and solar in California. The dGen model simulates the resource, economics, siting, load, and policy conditions for millions of potential distributed wind sites across the country. dGen agents use a discounted cash flow framework to evaluate in each year whether it is more economic to continue to consume gridsourced electricity or adopt a distributed wind or solar system. For this analysis, 100 agents were sampled per county sector, which is equivalent to 17,400 agents for the entire state.

This analysis uses the v2018 dGen model as documented in Cole et al. (2018). Further documentation of the wind- and solar-specific modules are available in Sigrin et al. (2016), McCabe et al. (2018), and Lantz et al. (2016). Four specific modifications were made to v2018 dGen for this analysis:

- Incorporation of California-specific data sets

- Incorporation of the Rooftop Energy Potential of Low Income Communities in America (REPLICA) data set on rooftop solar technical potential (Mooney and Sigrin 2018)

- Representation of cost-competitiveness between distributed wind and solar

- Updated parameters for retail electricity tariffs, both pre-TOU and post-TOU and for distributed wind capital costs.

These improvements in data fidelity constitute a significant overhaul to the model and provide a basis for calculating county-level economic potential estimates for distributed wind and solar under a scenario analysis framework.

\subsection{Model Updates}

\subsubsection{Implementation of New Data Sets}

Through an agreement with the California Energy Commission (CEC), we implemented several new California-specific data sets that improve model specification. Of special importance is an improvement in electrical demand data by county, sector, and utility for 1998-2017. This data set is complemented by CEC hourly load shape data ${ }^{2}$ for five major utilities in California ${ }^{3}$, which are representative of single-family and multifamily load profiles and usage levels in the residential sector and eight distinct building types in the nonresidential sectors. Together, these additional data improve constraints on the county-sector annual electrical demand, the load shapes, and the resulting fidelity of economic potential estimates for this analysis.

The REPLICA data set is another new data set we implemented in dGen. This data set provides estimates of residential rooftop solar technical potential at the census tract-level that are stratified by income, building type, and tenure. Similar to the CEC-provided load data, REPLICA data provide a better understanding of the census tract-level and sector-level constraints for building

\footnotetext{
${ }^{2}$ Our analysis assumes daily load profiles of electricity demand are inelastic to time changes in pricing. However, (EPRI 2008) indicates that TOU pricing may result in changes to temporal electricity usage.

${ }^{3}$ Los Angeles Department of Water \& Power, Pacific Gas \& Electric, Sacramento Municipal Utility District, San Diego Gas \& Electric, and Southern California Edison
} 
counts and rooftop potential by using lidar-based scans of the building stock in major metropolitan regions of California (Gagnon et al. 2016; Sigrin and Mooney 2018).

\subsubsection{Representation of California Time-of-Use Mandate}

In July 2015, the California Public Utility Commission issued Decision D.15.07-001, which provides direction to the California investor-owned utilities regarding the specific steps to reform residential electrical rates (CPUC 2018). Described henceforth as the TOU Mandate, this regulation resulted in default TOU rates to begin in 2019. The mandate is germane to the residential sector as nonresidential users are already mandated to subscribe to TOU-based rates. However, the exact policy details were unavailable to the authors at the time of publication; these include definitions of the TOU periods and their electricity prices. Given this uncertainty, we assume the enacted TOU rates will be comparable to voluntary opt-in TOU tariffs already available today in terms of the hours and price of each TOU period. We also assume the TOU transition will be revenue-neutral (i.e., that the average cost of electricity pre-TOU and postTOU is constant).

To simulate the TOU transition we collected data on current residential non-TOU, residential opt-in TOU, and nonresidential TOU rates using the Utility Rate Database (OpenEI 2018). To ensure full coverage, we identified five unique rates for each utility, including one for residential customers, two for commercial customers, and two for industrial customers, where the two nonresidential rates are for low-demand and high-demand customers. The exact value that delineates low- and high-demand customers depends on each individual utility's current tariffs and is not constant across all utilities. For the residential sector, we assume customers are not limited by any demand constraints placed on the residential TOU rate by the utility, and therefore are only represented by a single rate. Finally, where coverage is lacking (e.g., small municipal and cooperative utilities), we selected representative rates based on geographical distance to the nearest investor-owned utility. Table 1 includes a sample of these representative TOU rates. ${ }^{4}$

\footnotetext{
${ }^{4}$ Default TOU rate periods and pricing structure had not been announced at time of analysis on September $12,2018$. Any changes to policy after this date including changes or announcements of the default TOU periods were not incorporated in this report.
} 
Table 1. TOU Rates Used in the Study

\begin{tabular}{|c|c|c|c|c|}
\hline Utility Name & Sector & $\begin{array}{l}\text { Minimum } \\
\text { Demand (kW) }\end{array}$ & $\begin{array}{l}\text { Maximum } \\
\text { Demand (kW) }\end{array}$ & Rate Name \\
\hline $\begin{array}{l}\text { Pacific Gas } \\
\text { and Electric }\end{array}$ & Residential & 0 & $\mathrm{~N} / \mathrm{A}$ & $\begin{array}{l}\text { E-TOU Option B not dependent } \\
\text { on location }\end{array}$ \\
\hline $\begin{array}{l}\text { Pacific Gas } \\
\text { and Electric }\end{array}$ & Commercial & 0 & 75 & $\mathrm{~A} 1-\mathrm{TOU}$ \\
\hline $\begin{array}{l}\text { Pacific Gas } \\
\text { and Electric }\end{array}$ & Commercial & 75 & 500 & A10 Primary Voltage TOU \\
\hline $\begin{array}{l}\text { Pacific Gas } \\
\text { and Electric }\end{array}$ & Industrial & 500 & 1,000 & E19 Primary Voltage TOU \\
\hline $\begin{array}{l}\text { Pacific Gas } \\
\text { and Electric }\end{array}$ & Industrial & 1,000 & $\mathrm{~N} / \mathrm{A}$ & E20 Primary Voltage TOU \\
\hline $\begin{array}{l}\text { San Diego } \\
\text { Gas \& Electric }\end{array}$ & Residential & 0 & $\mathrm{~N} / \mathrm{A}$ & $\begin{array}{l}\text { TOU-DR Inland Baseline } \\
\text { Region }\end{array}$ \\
\hline $\begin{array}{l}\text { San Diego } \\
\text { Gas \& Electric }\end{array}$ & Commercial & 20 & 200 & AL-TOU Primary \\
\hline $\begin{array}{l}\text { San Diego } \\
\text { Gas \& Electric }\end{array}$ & Commercial & 200 & 500 & AL-TOU Primary \\
\hline $\begin{array}{l}\text { San Diego } \\
\text { Gas \& Electric }\end{array}$ & Industrial & 500 & 1,000 & AL-TOU Primary \\
\hline $\begin{array}{l}\text { San Diego } \\
\text { Gas \& Electric }\end{array}$ & Industrial & 1,000 & $\mathrm{~N} / \mathrm{A}$ & AL-TOU Primary \\
\hline $\begin{array}{l}\text { Southern } \\
\text { California Edison }\end{array}$ & Residential & 0 & $\mathrm{~N} / \mathrm{A}$ & D-A \\
\hline $\begin{array}{l}\text { Southern } \\
\text { California Edison }\end{array}$ & Commercial & 20 & 200 & GS-2 TOU A at $220 \mathrm{kV}$ \\
\hline $\begin{array}{l}\text { Southern } \\
\text { California Edison }\end{array}$ & Commercial & 200 & 500 & GS-3 TOU A at $220 \mathrm{kV}$ \\
\hline $\begin{array}{l}\text { Southern } \\
\text { California Edison }\end{array}$ & Industrial & 500 & 1,000 & TOU-8 \\
\hline $\begin{array}{l}\text { Southern } \\
\text { California Edison }\end{array}$ & Industrial & 1,000 & $\mathrm{~N} / \mathrm{A}$ & TOU-8 \\
\hline
\end{tabular}

\subsubsection{Competition Among Distributed Generation Technologies}

We consider the simultaneous cost-competitiveness of distributed wind and solar, relative to each technology and versus continuing to purchase grid-sourced electricity. Our comparison of technologies only considers economic factors, specifically, the 20-year NPV of the distributed generation system. In actuality, additional factors might influence consumer technology adoption, including familiarity with a technology, whether peers have adopted it, visual appearance, hassle, and perceived risk - though these factors are not considered here.

For the sake of comparability, agents with identical attributes are used to evaluate each technology. These include siting availability of each technology, wind and solar resource profiles 
at the site, load profiles, and retail rates. For instance, this reflects that distributed wind might not be feasible at a particular urban site, whereas solar might be.

A technology is deemed "competitive" only if its normalized NPV is positive. If one technology is competitive, it is the sole technology selected; if both technologies have a negative normalized NPV, neither is selected. If both technologies are competitive, Equation 1 (next page) is used to determine the market share for each technology. For the sake of comparability, the NPV is normalized by the system capacity (NPV/kW), because sites could differ in their technical potential.

Let $M_{w}$ and $M_{s}$ be the market shares of wind and solar respectively and $N P V_{w}$ and $N P V_{s}$ their normalized NPV, and then:

$$
\begin{aligned}
M_{w} & =\frac{N P V_{w}^{2}}{N P V_{w}^{2}+N P V_{s}^{2}} \\
M_{s} & =\frac{N P V_{s}^{2}}{N P V_{w}^{2}+N P V_{s}^{2}}
\end{aligned}
$$

The mathematical properties of Equations 1 and 2 are twofold. First, the technology with the greater economic ${ }^{5}$ return will increase market share at a quadratic rate, such that consumer preference converges when the NPVs are substantially different. Second, the equations avoids a "knife edge," so that one technology is not wholly ignored if it has a marginally-worse NPV than the other technology. This formulation reflects the concept that consumers prefer technologies with better economic returns but might still adopt a technology with inferior economic return (though at lower rates).

\subsection{Scenario Analysis Framework}

We use a scenario-based approach to identify the relative effect of the TOU transition on the long-term economic outlook for distributed wind and solar in California. The scenarios are not intended to be prescriptive, but they provide an array of plausible future market conditions to explore sensitivities of economic potential. Though several sensitivities could be considered, our analysis uses distributed generation capital costs and rate design as the primary sensitivities of interest.

\section{Cost and Performance Scenarios for Distributed Generation Technologies}

Distributed wind and solar cost and performance projections, which were developed based on a combination of current market data, were designed to explore a range of plausible market outcomes. For distributed wind, two distributed capital costs projections were developed (Table 2). The High scenario is based on the Reference cost projection from Lantz et al. (2016). Since 2016, distributed wind capital cost reductions have progressed faster than anticipated in previous reports, necessitating a new Mid cost schedule. Three methods were used to better align

\footnotetext{
${ }^{5}$ Our analysis only compares the economic potential of technologies to determine market share; it does not incorporate consumer behavioral aspects that would affect the potential adoption of either technology.
} 
our capital expenditure (CAPEX) schedules with non-public data available to NREL on current distributed wind projects:

- Applying a 15\% cost reduction from the Breakthrough (Deployment) cost projection from Lantz et al. (2016) for turbines below $50 \mathrm{~kW}$

- Matching the NREL 2018 Annual Technology Baseline (ATB) (NREL 2018) TechnoResource Group (TRG) 4 schedule for land-based wind for turbines that are 1.5-MW and greater

- Making a proportional adjustment from the 1.5-MW schedule to turbines sized from $50 \mathrm{~kW}$ to $1 \mathrm{MW}$, using the ratios from the Breakthrough (Deployment) cost projection.

Table 2. Distributed Wind Capital Cost Scenarios

\begin{tabular}{|c|c|}
\hline Schedule Name & Description \\
\hline High & Reference values from the Lantz (2016) \\
\hline Mid & $\begin{array}{l}\text { CAPEX schedules for turbines that } 1.5 \mathrm{MW} \text { and greater follow the ATB TRG } 4 \\
\text { schedule. } \\
\text { Turbines below } 50 \mathrm{~kW} \text { are priced at } 15 \% \text { reduction from Breakthrough values from } \\
\text { Lantz (2016). } \\
\text { Turbines that are between } 50 \mathrm{~kW} \text { and } 1 \mathrm{MW} \text { are proportioned from the } 1.5-\mathrm{MW} \\
\text { schedule using Breakthrough value ratios. }\end{array}$ \\
\hline
\end{tabular}

For distributed solar, three cost scenarios were used; the Low and Mid Cost scenarios are from the ATB (NREL 2018), and a High cost scenario is mostly based on the 2018 Tracking the Sun report from Lawrence Berkeley National Laboratory (Barbose and Darghouth 2018). The High Cost Solar cost schedule follows the same trajectory as the Mid Cost scenario, but it is uniformly 35\% higher than the Mid Cost price for each year. The 35\% mark-up is made to align the 2018 solar capital costs with those reported for California in 2018 (i.e., from the Tracking the Sun report). For both technologies, external to the cost and performance assumptions, we have also included a scenario in which the TOU mandate is in effect, and a counterfactual scenario in which non-TOU rates persist, to better understand the effect of TOU tariffs on each technology's economic viability.

Table 3. Full Scenario Matrix, Including Scenario Names, Wind and Solar Cost Schedules, and the Rate Case Used in Each Scenario

\begin{tabular}{|l|l|l|l|}
\hline Scenario Name & Wind Cost Schedule & Solar Cost Schedule & Rates \\
\hline Baseline & Mid & 2018 ATB Mid & Current rates, no TOU \\
\hline TOU Baseline & Mid & 2018 ATB Mid & TOU on in 2020 \\
\hline High Cost Wind & High & 2018 ATB Mid & Current rates, no TOU \\
\hline TOU High Cost Wind & High & 2018 ATB Low & TOU on in 2020 \\
\hline TOU High Cost Solar & Mid & 2018 LBNL ${ }^{\text {a High }}$ & TOU on in 2020 \\
\hline TOU Low Cost Solar & Mid & 2018 ATB Low & TOU on in 2020 \\
\hline
\end{tabular}

a Lawrence Berkeley National Laboratory (Barbose and Darghouth 2018). 


\section{Results}

For this case study, we analyze the economic potential of wind and solar in California under various cost and electricity rate scenarios. A primary goal of this study is to understand the effects of TOU rates on the intra-technology economic potential of distributed wind and solar. Additionally, we identify the effects of capital cost on wind's economic competitiveness by linearly varying the capital cost of wind relative to solar costs. Finally, we identify the specific regions (counties) and sectors in California that are particularly competitive for one technology — with the aim of understanding where initial markets might develop.

\subsection{Implications of TOU Transition}

\subsubsection{Economic Potential of Distributed Wind and Distributed Solar}

Our model projects that the economic potential of distributed wind could decrease when shifting from the current tiered rate structure to a non-tiered TOU rate structure; however, distributed solar may experience an increase in economic potential.

Under the Baseline scenario, distributed wind sees modest, yet notable, competitiveness with distributed solar. From 2019 to 2021, distributed wind economic potential drops to around $180 \mathrm{MW}$ before consistently growing to just under $1.5 \mathrm{GW}$ by 2030 . The initial drop in wind economic potential can be attributed to the reduction and expiration of the federal investment tax credit from 2018 to 2022 as well as the expiration of California's Self-Generation Incentive Program by the end of 2020. The subsequent growth to $1.5 \mathrm{GW}$ is a result of the continued decline in CAPEX for distributed wind in all turbine sizes.

The implementation of TOU rates in our TOU Baseline scenario has a slight negative impact on the economic competitiveness of distributed wind as seen in Figure 1 (next page). Distributed wind with and without TOU experience similar trends of dropping from 2019 to 2021 before increasing in economic potential. With TOU implementation, however, wind economic potential reaches just over $1.3 \mathrm{GW}$ by 2030 , compared to $1.5 \mathrm{GW}$ under current rate structures. Though distributed wind experiences a minor decrease in economic potential, our results indicate that over $1 \mathrm{GW}$ of potential still exists in California by 2030. On the other hand, TOU provides a small improvement in distributed solar economic potential relative to the Baseline, as shown in Figure 2 (next page). Distributed solar economic potential in our TOU Baseline scenario grows at a slightly higher rate than the Baseline scenario. In 2030, distributed solar under TOU surpasses $44 \mathrm{GW}$, which is about $800 \mathrm{MW}$ higher than the Baseline scenario.

Although the economic potential for distributed wind is lower than it is for solar, and its competitiveness decreases modestly with TOU, a noteworthy number of distributed wind projects with economic viability still exists in California. The $1.3 \mathrm{GW}$ of economic potential that our model projects in 2030 corresponds to roughly 80,000 distributed wind projects (Figure 3). When breaking these projects down by system size, it becomes evident that smaller-sized turbines comprise a clear majority of the projects. More specifically, turbines sized from $2.5 \mathrm{~kW}$ to $20 \mathrm{~kW}$ constitute less than one-third of the $1.3 \mathrm{GW}$ of economic potential but amount to over 70,000 projects. See Appendix A for the full economic potential results by year, scenario, and technology. 


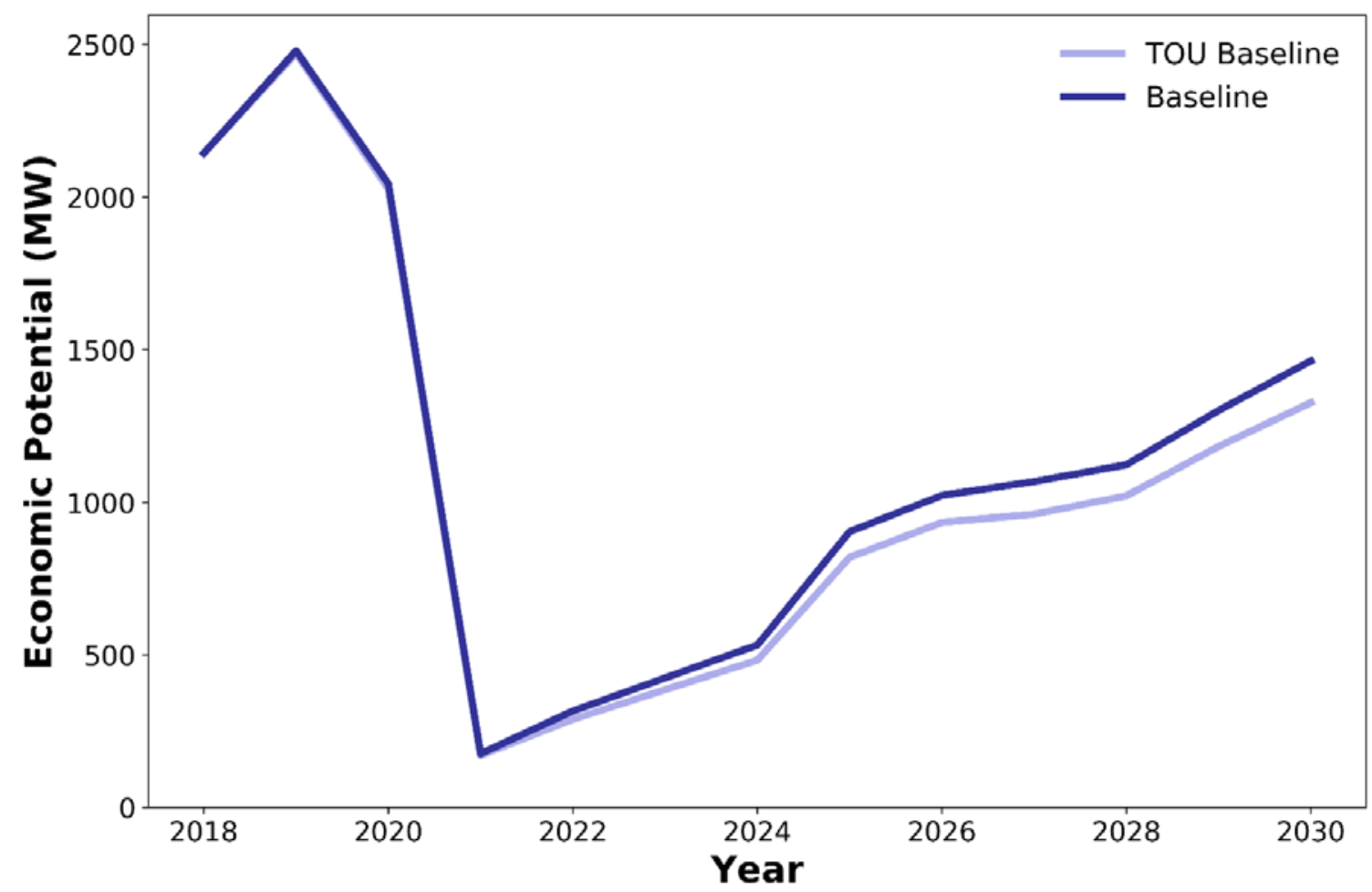

Figure 1. Effect of TOU mandate on economic potential of distributed wind

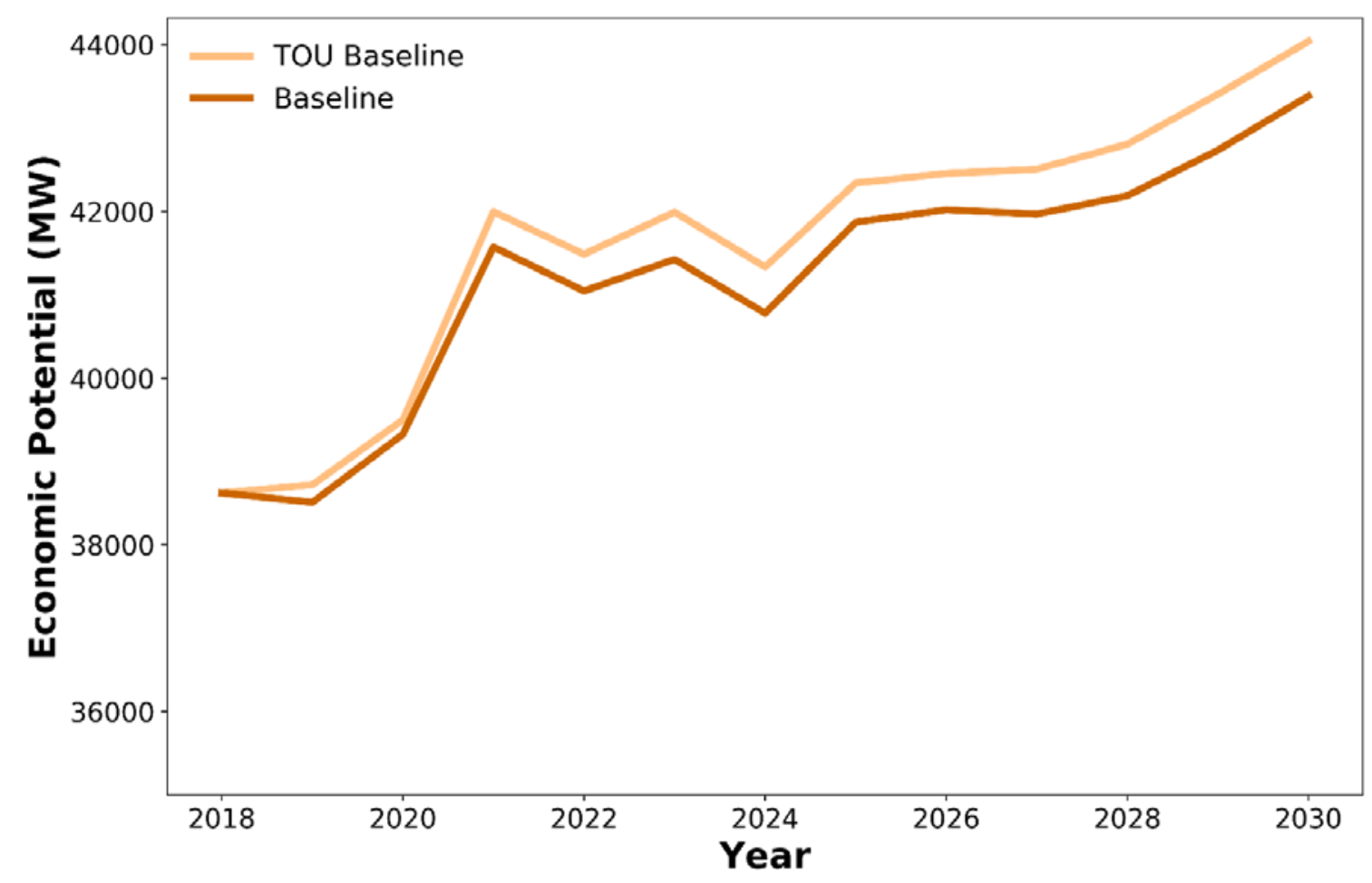

Figure 2. Effect of TOU mandate on economic potential of distributed solar 


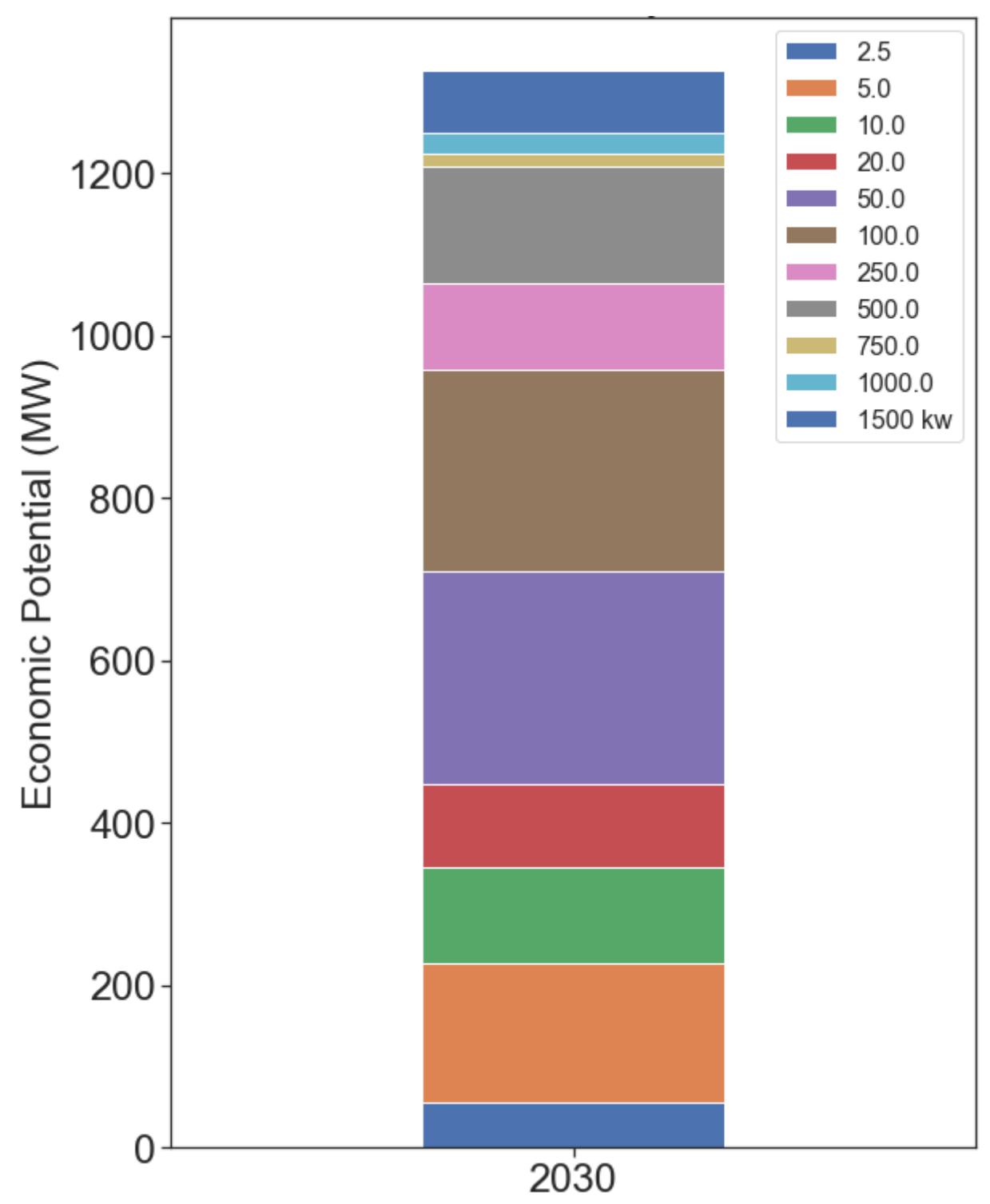

Figure 3. Breakdown of distributed wind economic potential (above) and number of projects (below, next page) by turbine size (kW) in 2030 


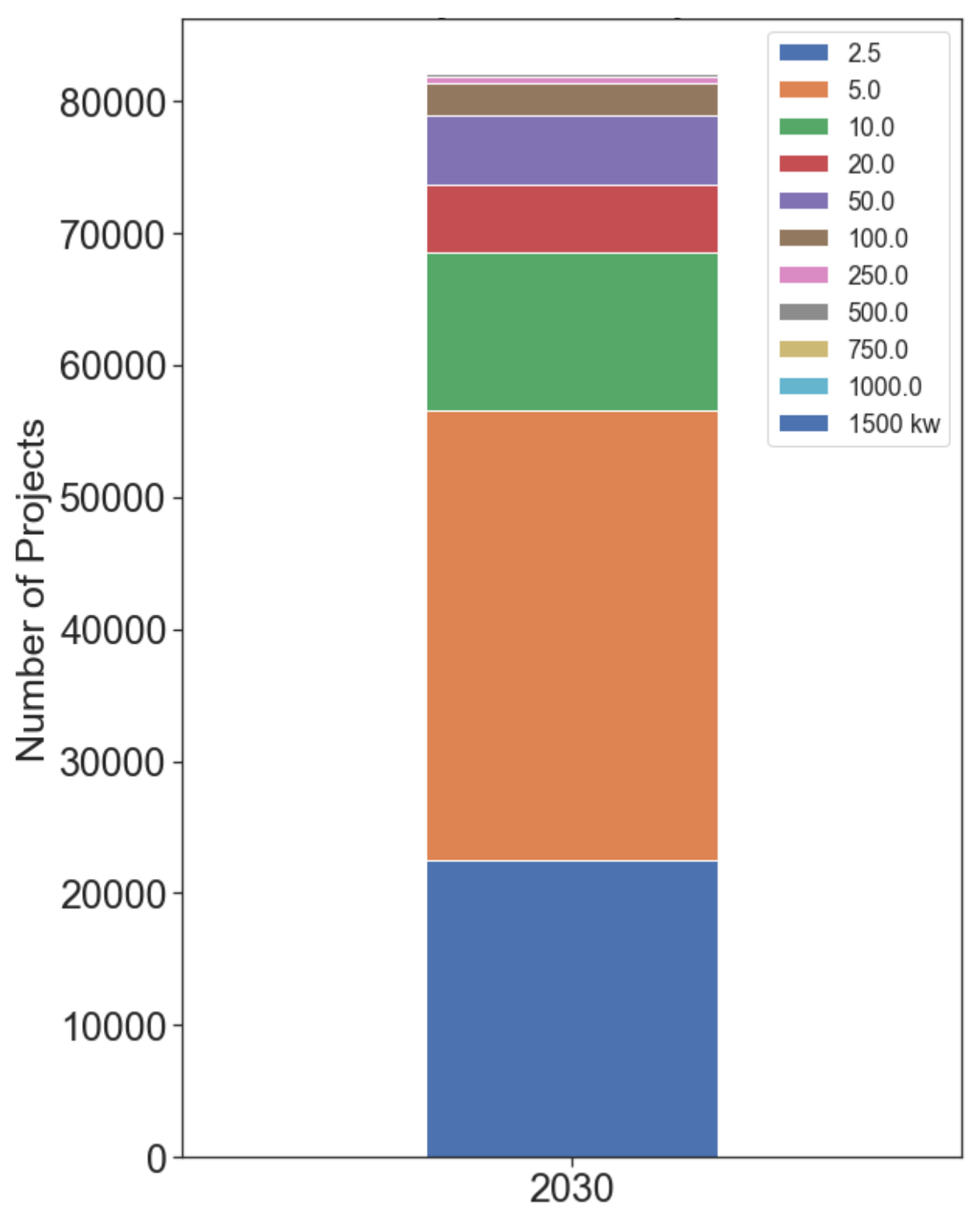

Because we model commercial and industrial customers to already subscribe to a TOU rate, the only change in economic potential in the TOU Baseline scenario occurs in the residential sector (Figure 4, next page). The residential sector sees distributed wind potential of roughly $550 \mathrm{MW}$ by 2030 in the Baseline, which reduces to just over $400 \mathrm{MW}$ in the TOU Baseline scenario. The economic potential of distributed solar in the residential sector improves from $15.5 \mathrm{GW}$ to 16.2 GW in 2030. Next, we explain the opposing reactions to TOU implementation by examining how each technology responds to the TOU rate structures as compared to the current tiered rate structures. 

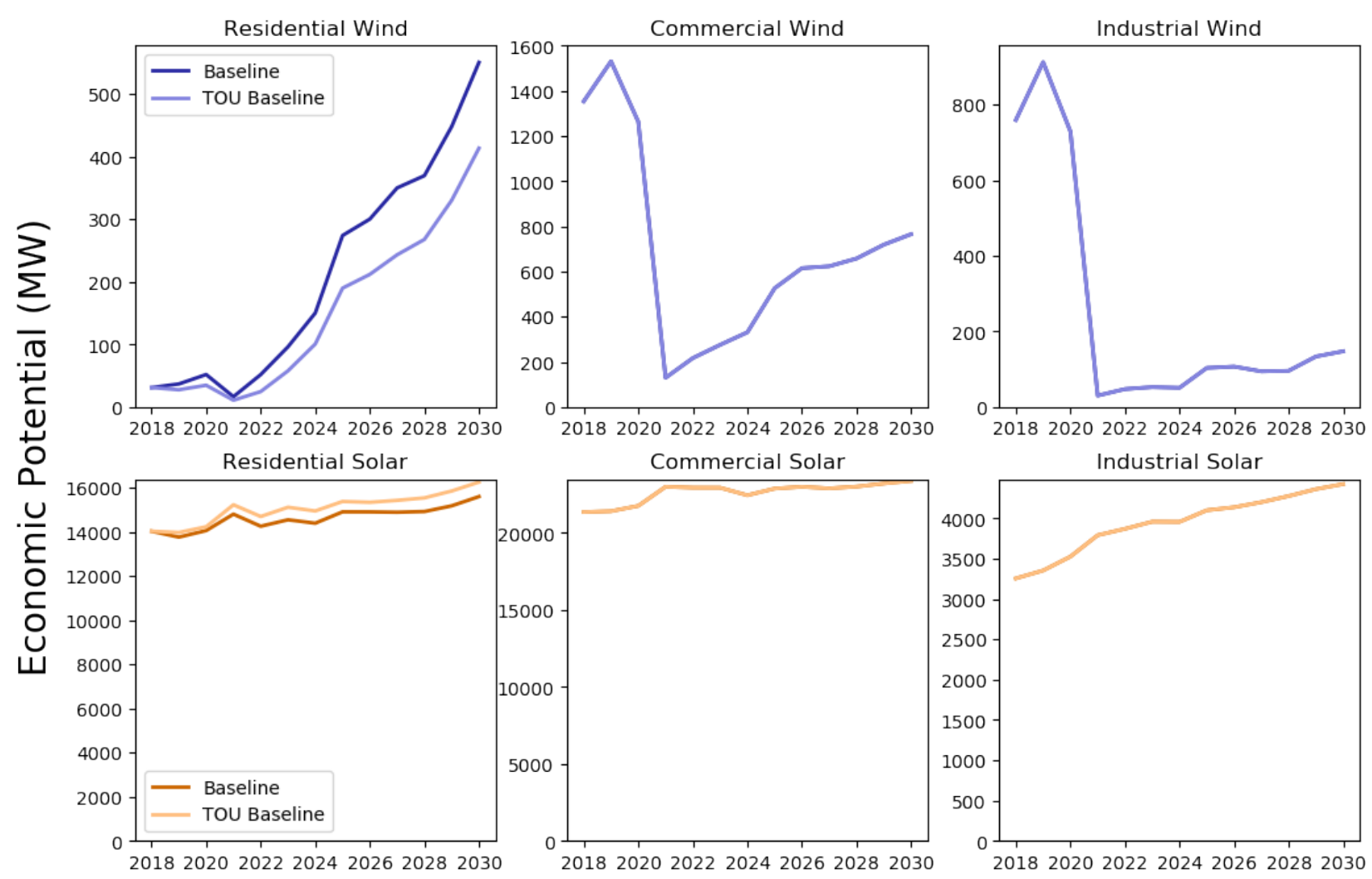

Figure 4. Economic potential of distributed wind (top row) and distributed solar (bottom row) by sector

\subsubsection{Examination of Distributed Wind Economic Potential Decline Under TOU}

Contrary to our expectation, the TOU periods and rates as modeled in our study do not seem to substantially affect distributed wind economic potential. This directional conclusion is based on nuances of current rates and could vary based on the final tariffs and the specific load profiles of individual customers. We explain the effect of the TOU transition with two phenomena-first, wind generation actually exhibits only a modest correlation with the TOU peak periods ${ }^{6}$ and, second, the effect of changes away from daily-tiered rates is larger than the effect of TOU period correlation.

For current residential tiered rates, the tier into which a customer falls in each hour depends on the customer's total electricity usage up until that hour; once the customer's daily baseline allowance is reached, subsequent consumption in that day is billed at the next tiered rate. A customer's hourly usage is calculated based on their net electricity consumption from energy coming in minus any excess energy going out. Owning a distributed generation system would allow a customer to reduce their hourly net energy usage, thus decreasing their cumulative energy usage and delaying their entry into a higher-tiered rate. Avoiding higher tiers results

${ }^{6}$ TOU rate periods modeled in this analysis are reflective of TOU options offered by utilities as of September 12 , 2018. Any changes to policy after this date, including changes or announcements of the default TOU periods were not incorporated in this report. 
in bill savings. By reducing the net load in each hour, a distributed wind system can delay or avoid higher tiers under the current rate plan.

Compared to mechanism of savings explained above, a distributed wind system under TOU does not provide an advantage in California because of the low wind capacity factors and the misalignment of electricity prices and wind resource potential. For distributed wind to be valuable under TOU, it must generate during peak periods to maximize bill savings; the TOU peak periods are set time intervals in the evening which align with the utility's higher electricity demand. In contrast to tiered rates, the hourly rates for TOU do not shift based on a customer's usage; they are set rates for set periods. Additionally, TOU prices are higher in summer months than winter months to correspond with higher seasonal demand. In general, our mesoscale wind resource data indicate that residential wind capacity factors in California are lower in summer months than winter months. Equally significant is that in summer months, wind has a higher capacity factor in the night and early morning, and it trails off before the evening hours. Subsequently, distributed wind has lower generation during the peak periods and lower generation overall during the months with higher rates. The TOU rates do not allow wind to take noteworthy advantage of nighttime or early morning generation, but the current tiered rates do.

Under the current tiered rates, which depend on a customer's usage, nighttime and early morning wind generation can push back the onset of higher-tiered rates to later hours, after some hours of peak evening demand have already taken place. Thus, with hours of higher demand billed at a lower rate with a wind system than without one, the current tiered rates allow a distributed wind system to offer greater savings than TOU rates. ${ }^{7}$

To illustrate this phenomenon, below are three figures that depict a sample day for an Southern California Edison customer with a 10-kW wind system. In Figure 5, the load profile is from a single summer weekday in San Bernardino County, and the wind profile is the average hourly summer capacity factors for San Bernardino County. ${ }^{8}$ We use Southern California Edison's baseline allowance for San Bernardino County, while the prices for the tiered structure and TOU structure were chosen such that the cumulative daily bill would be equal in the two structures with no distributed wind system. By equalizing the rates without a wind system, we can directly observe the effect of the distributed wind system's performance and rate design on the cumulative bill.

Figure 6 shows tiered rates with and without the $10 \mathrm{~kW}$ system as well as net electricity demand. Distributed wind's early generation pushes back the hour when the higher-tiered rate kicks in, allowing higher demand to be priced at a lower value. This figure also illustrates the relationship between demand and pricing for TOU, specifically that high demand still aligns with TOU peak period prices because wind generation is not strong in those hours. Figure 7 shows that with tiered rates, the customer's total bill for the day was roughly $\$ 20$, compared to about $\$ 24$ under TOU rates.

\footnotetext{
${ }^{7}$ Results may vary if multitiered rate structures are used in tandem with TOU.

${ }^{8}$ San Bernardino County was chosen for this example because it has a notably high number of installations of 10-kW systems (Folkman et al. 2016).
} 


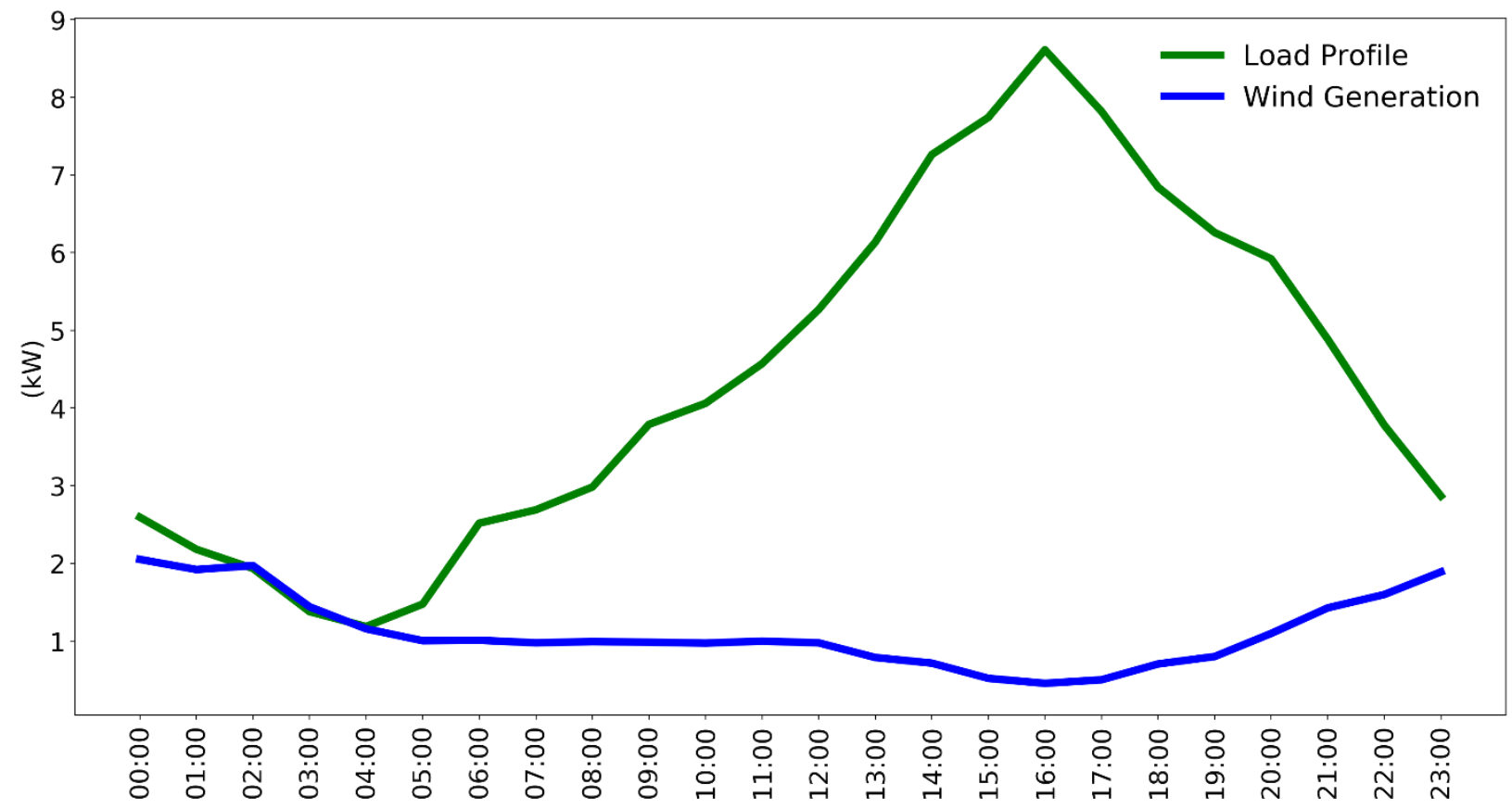

Figure 5. A sample load profile from a summer weekday for a Southern California Edison customer in San Bernardino County overlaid with average summer generation in San Bernardino County with a 10-kW wind system

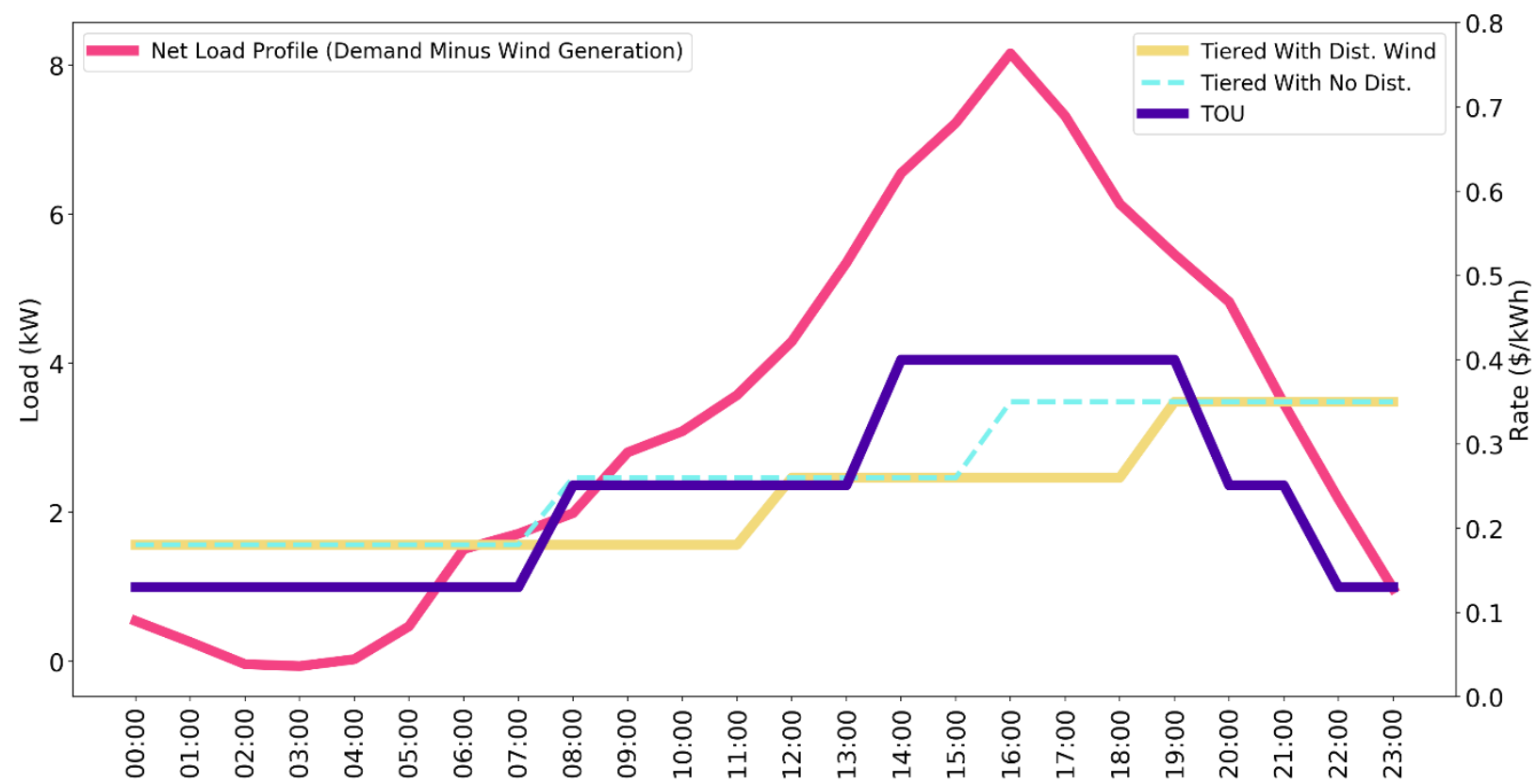

Figure 6. Overlay of net electricity demand (left axis), hourly rates for a wind system under tiered rates (right axis), and no wind system under tiered rates (right axis)

TOU hourly rates with and without a system (right axis) are equal. 


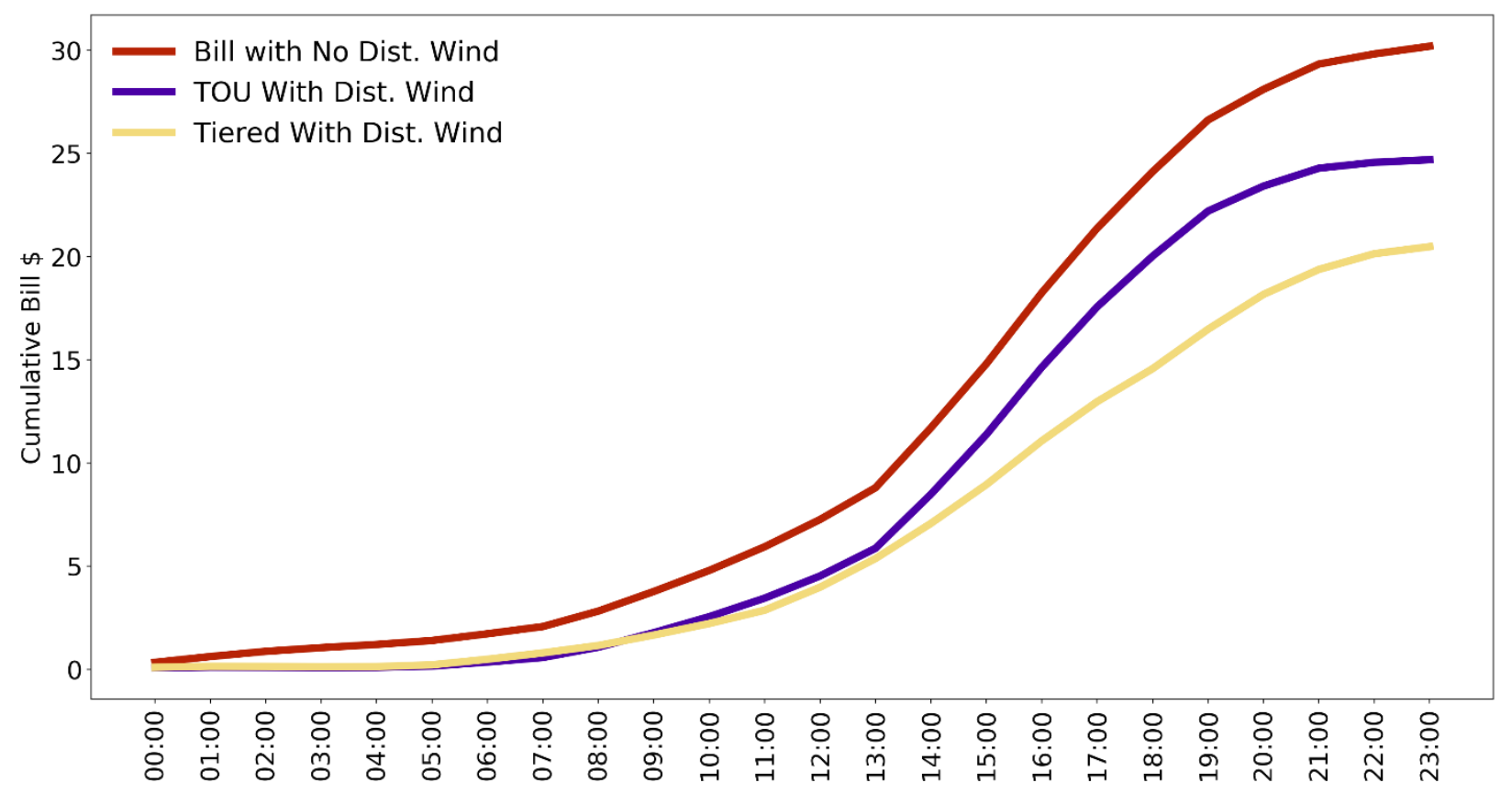

Figure 7. Comparison of cumulative bills for a wind system under TOU and a wind system under a tiered rate structure

Bills with no wind systems are equal under the two rate structures.

Distributed wind under TOU becomes more advantageous than current tiered rates at higher capacity factors; however, the generally lower capacity factors for wind in California keep it from significantly avoiding the cost of on-peak prices, therefore tipping the scale in favor of current tiered rates.

On the other hand, distributed solar can take advantage of higher capacity factors and the periods of the day when capacity factors rise. As illustrated in Figure 8, solar generation predominantly occurs in the "off-peak" period, but depending on the utility's defined TOU periods, solar can still generate substantially in the "on-peak" hours. 

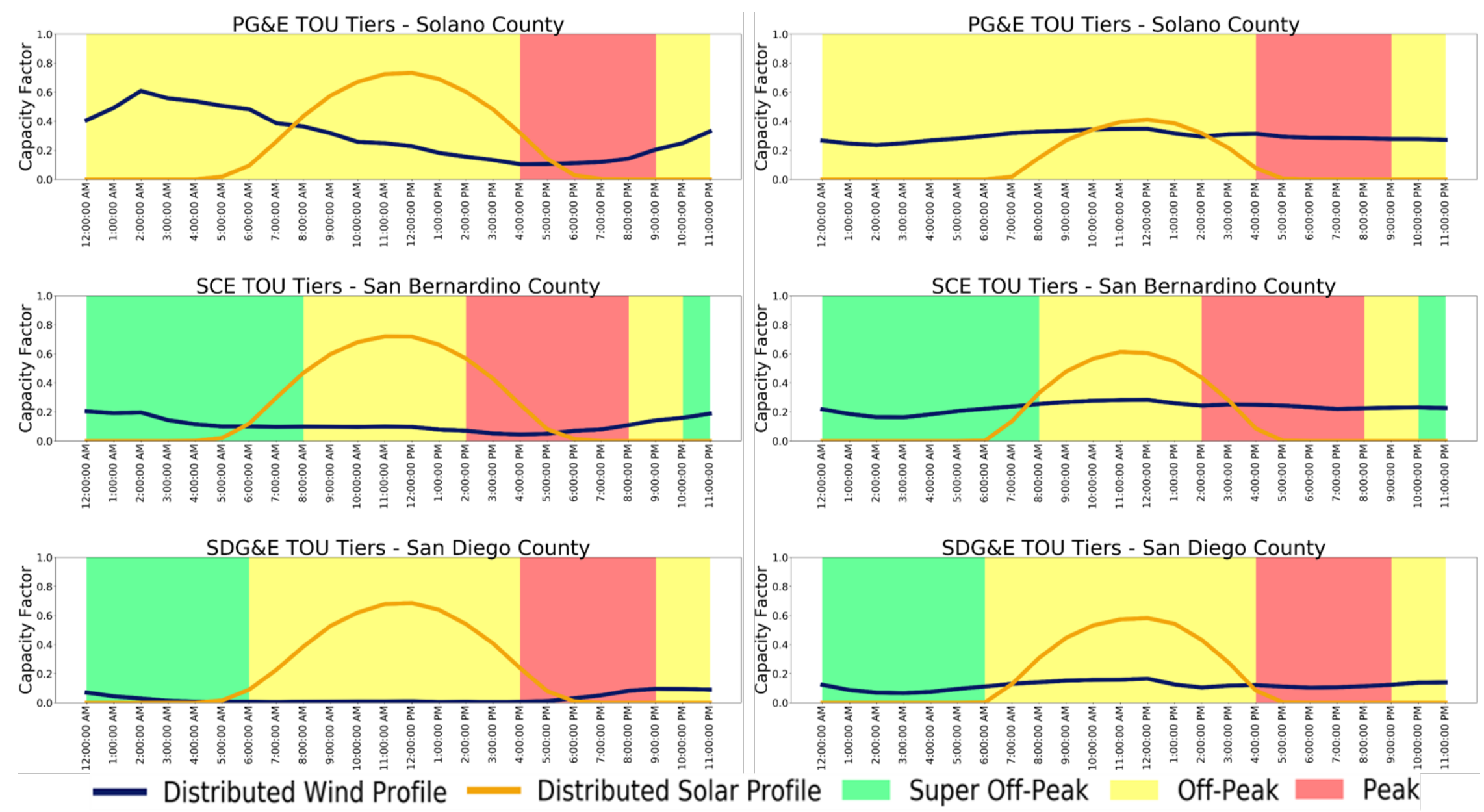

Figure 8. Overlay of residential TOU tiers with summer (left) and winter (right) capacity factor profiles

\subsection{Effect of Cost on Distributed Wind Potential}

Each agent in dGen evaluates a distributed solar system, distributed wind system, or no system at all. The competitive nature of this selection can make it less clear how cost affects the economic potential of distributed wind. To better understand the effect of cost on the economic viability of distributed wind the TOU Baseline and TOU High Cost Wind scenarios were run with no solar competition. 
In these scenarios, the agents only evaluate a distributed wind system or no system at all; distributed solar is not presented as an option. By modeling distributed wind with no solar competition and under the same rate structure, we can isolate for how distributed wind capital cost affects its economic potential. Additionally, comparing these results to our original results will provide a better understanding of how competition with distributed solar affects the market for distributed wind. The model was also run for distributed solar with no distributed wind competition under the TOU Baseline, TOU High Cost Solar, and TOU Low Cost Solar scenarios.

\subsubsection{Potential of Distributed Wind in an Environment with and without Competition}

The cost of energy relative to that of distributed solar is a critical driver of the economic competitiveness of distributed wind. In an environment where distributed wind does not compete with distributed solar, the economic potential in the TOU Baseline scenario reaches about $7.5 \mathrm{GW}$ in 2030. Table 4 details the system CAPEX in 2030 that were used in the TOU Baseline scenario compared to the TOU High Cost Wind scenario (See Appendix B for the full annual CAPEX schedules used in this analysis for distributed wind). With the CAPEX in the TOU High Cost Wind scenario, the economic potential is reduced by almost $75 \%$ from the TOU Baseline scenario. These results, in Figure 9, underscore the heavy dependence of distributed wind viability on the cost of installation for all turbine sizes.

Table 4. CAPEX for Distributed Wind Under the TOU Baseline and TOU High Cost Scenarios in 2030

\begin{tabular}{|r|r|r|}
\hline Turbine Size $(\mathbf{k W})$ & $\begin{array}{l}\text { TOU Baseline CAPEX } \\
\text { in } 2030(\mathbf{\$} / \mathbf{k W})\end{array}$ & $\begin{array}{l}\text { TOU High Cost Wind CAPEX } \\
\text { in } 2030(\$ / \mathbf{k})\end{array}$ \\
\hline 2.5 & 3,391 & 7,923 \\
\hline 5 & 2,763 & 6,515 \\
\hline 10 & 2,320 & 5,520 \\
\hline 20 & 2,006 & 4,816 \\
\hline 50 & 1,489 & 3,497 \\
\hline 100 & 1,489 & 3,231 \\
\hline 250 & 1,489 & 2,680 \\
\hline 500 & 1,489 & 2,417 \\
\hline 750 & 1,489 & 2,263 \\
\hline 1,000 & 1,489 & 1,960 \\
\hline 1,500 & 1,381 & 1,818 \\
\hline
\end{tabular}




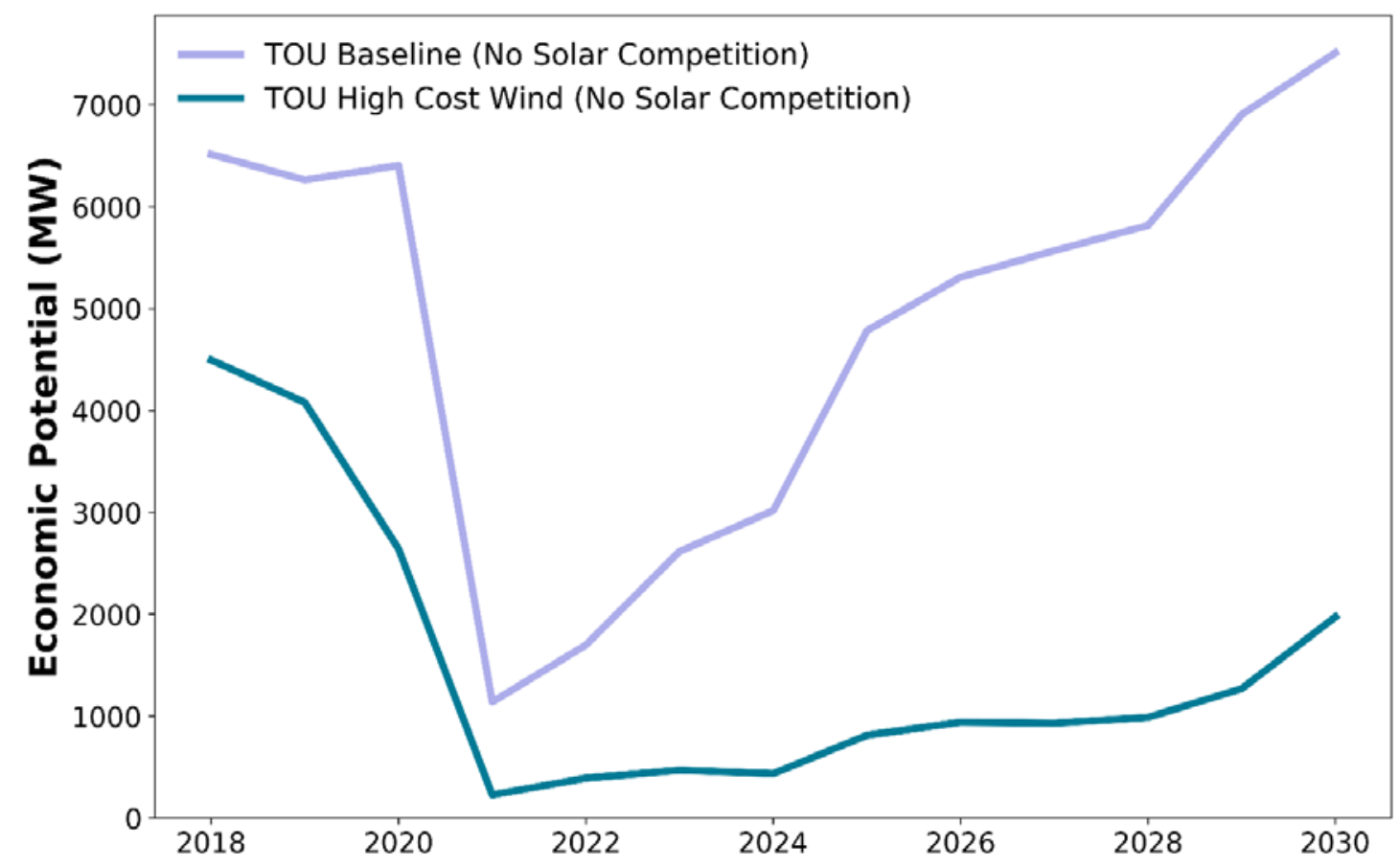

Figure 9. Economic potential of distributed wind in the TOU Baseline and TOU High Cost Wind scenarios with no solar competition

When introducing distributed solar competition, the importance of cost becomes even more apparent for distributed wind (Figure 10). Because of the higher system cost per $\mathrm{W}$ relative to distributed solar and lower capacity factors, distributed wind relinquishes over $6 \mathrm{GW}$ of economic potential in the TOU Baseline scenario in 2030. Higher costs for wind further suppress its economic potential. Under the TOU High Cost Wind cost schedule with solar competition, distributed wind reaches only $250 \mathrm{MW}$ of economic potential in 2030, followed by a drop and slow rise to $150 \mathrm{MW}$ by 2050 . 


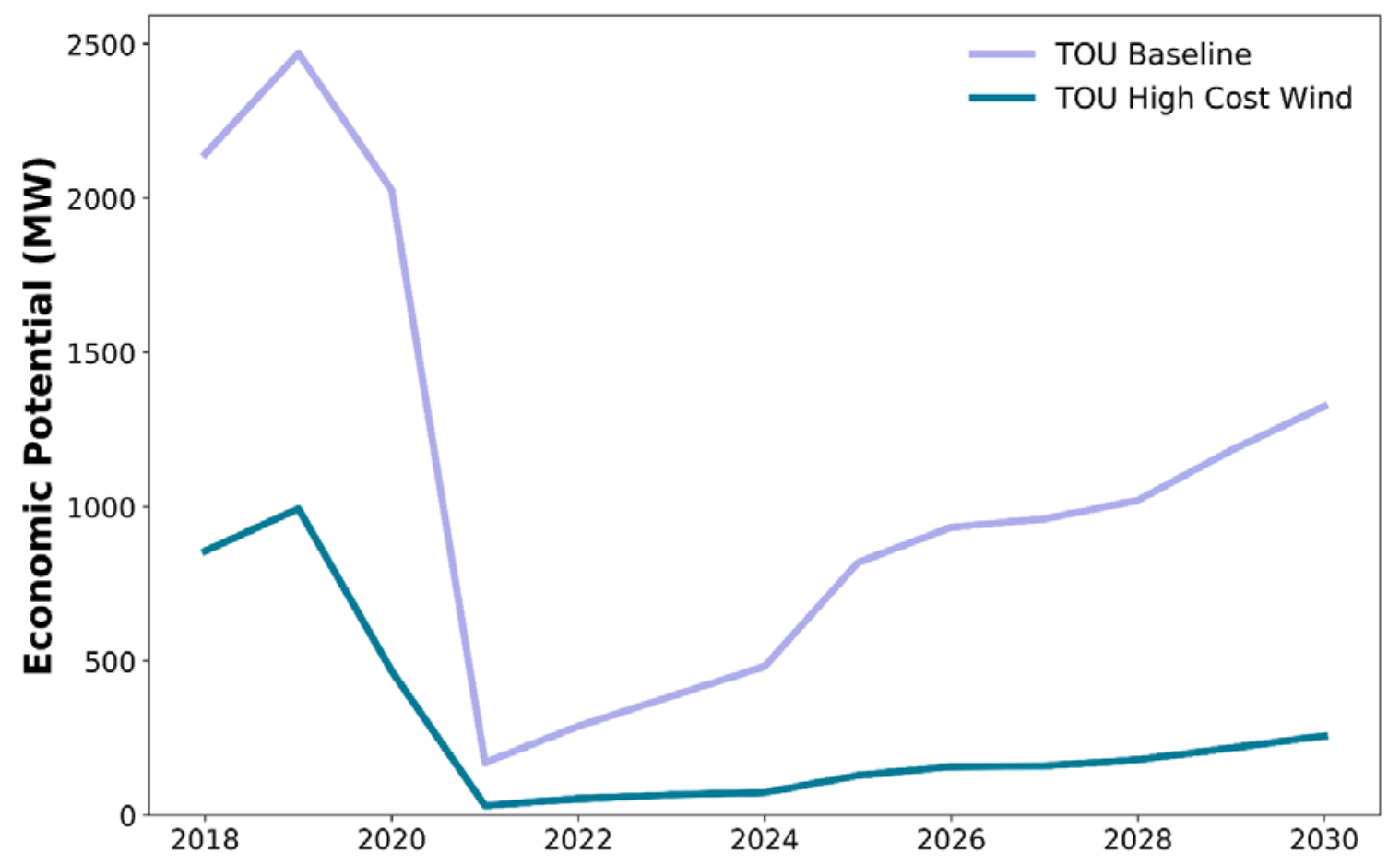

Figure 10. Economic potential of distributed wind in the TOU Baseline and TOU High Cost Wind scenarios with solar competition

\subsubsection{Potential of Distributed Solar in a Noncompetitive and Competitive Environment}

The economic potential of distributed solar, when competing with distributed wind, does not deviate as notably from the results with no competition, because distributed wind captures less than $1.5 \mathrm{GW}$ of economic potential at any given point (Figures 11, 12). Even with high solar costs and competition from distributed wind, the economic potential of solar drops only $2.6 \mathrm{GW}$ from its previous value of $45 \mathrm{GW}$ with mid costs and no competition. 


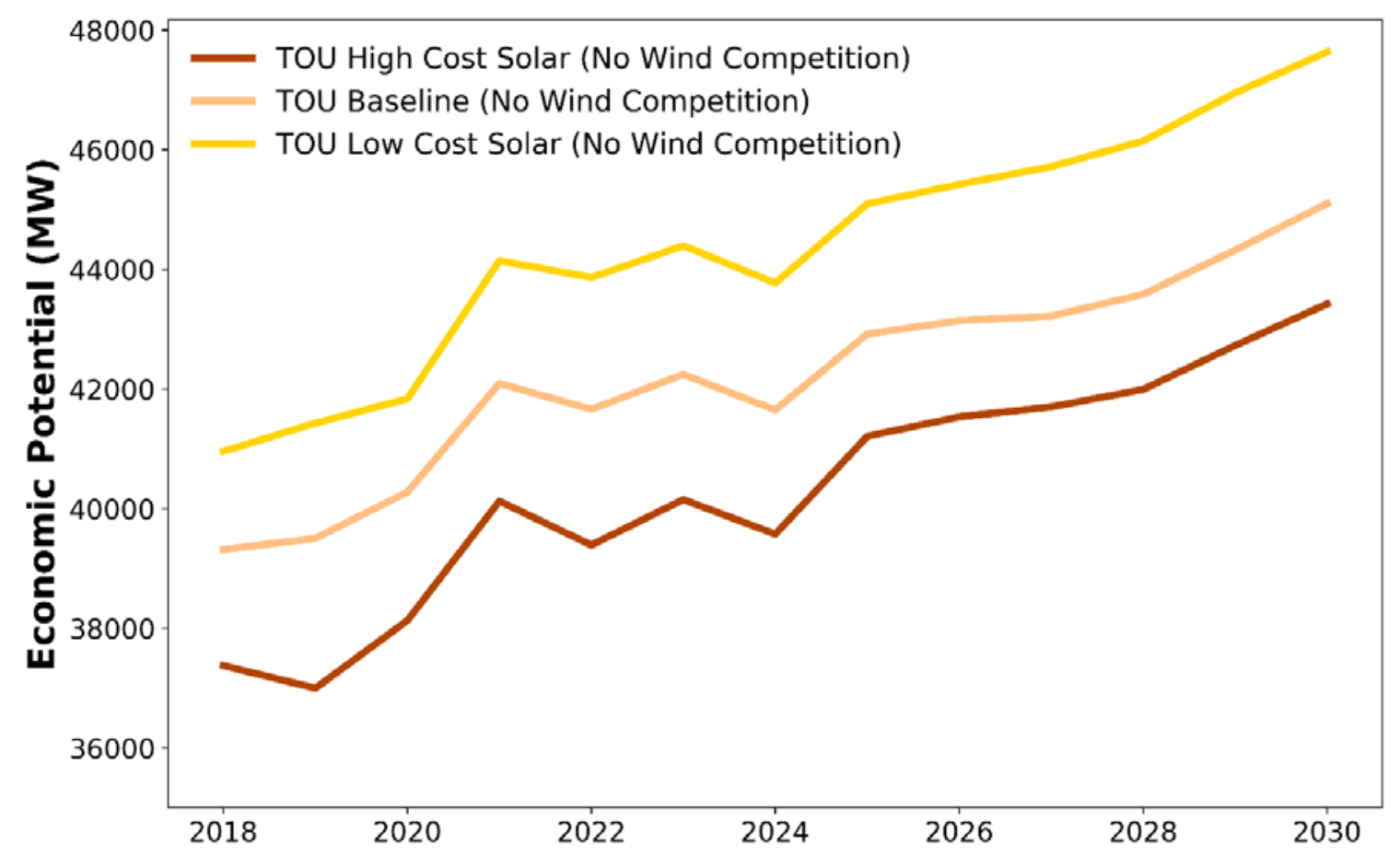

Figure 11. Economic potential of distributed solar in the TOU High Cost Solar, TOU Baseline, and TOU Low Cost Solar scenarios with no wind competition

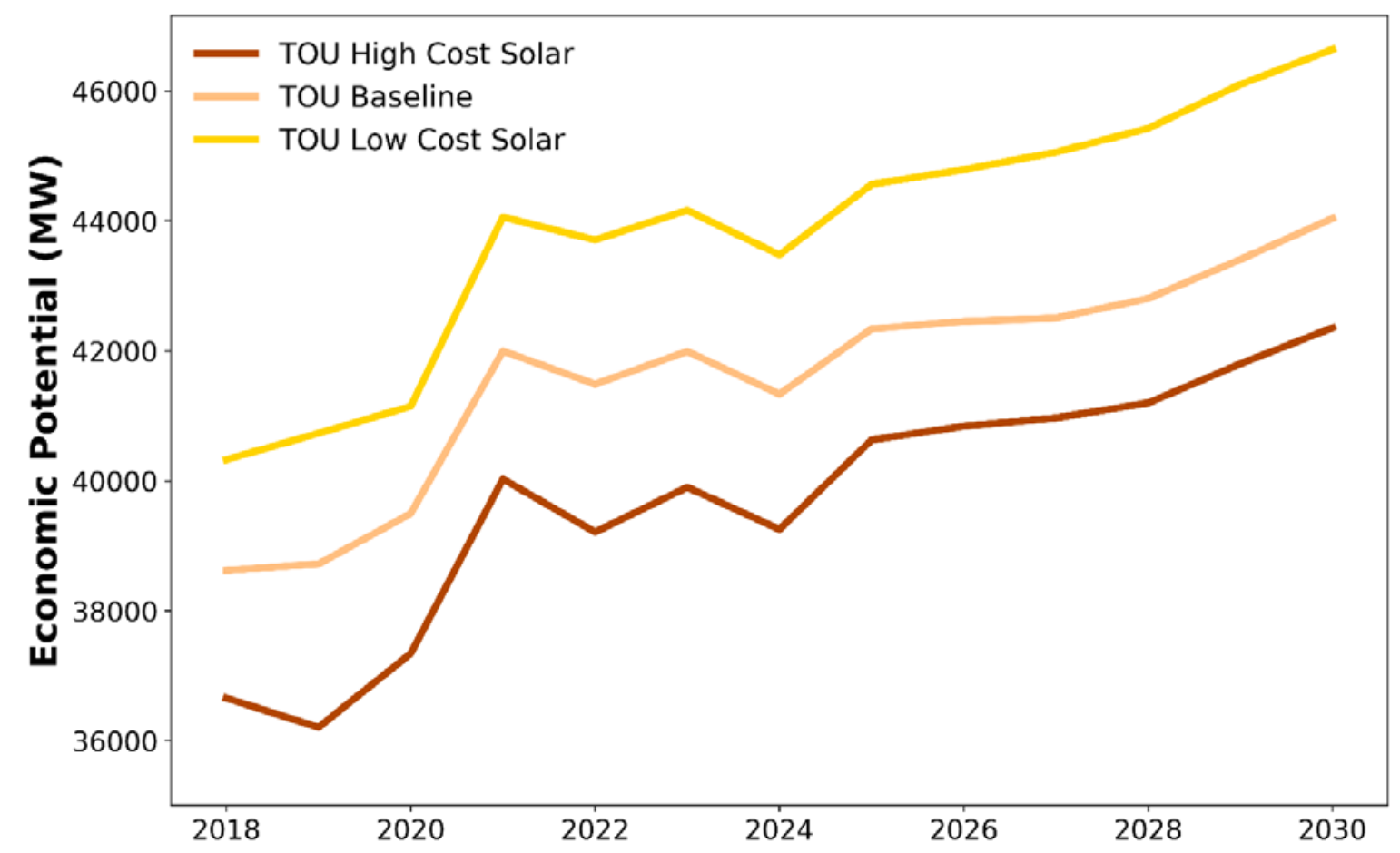

Figure 12. Economic potential of distributed solar in the TOU High Cost Solar, TOU Baseline, and TOU Low Cost Solar scenarios with wind competition 


\subsubsection{Sensitivity of Distributed Wind Potential to Opportunistic Cost Improvements}

The dGen model projects at least $1 \mathrm{GW}$ of distributed wind economic potential by 2030 . To grow this market, a decline in system CAPEX is needed. To evaluate the sensitivity of market growth to additional cost reduction, we assess the change in economic potential as lower total CAPEX are assumed. We focus first on the results in 2020 and second on the results in 2030. As shown in Figure 13 (next page), economic potential seems to proliferate in 2020, when costs decline below $\$ 3 / \mathrm{W}$. A reduction from $\$ 4 / \mathrm{W}$ to $\$ 3 / \mathrm{W}$ appears to double the economic potential of the residential sector turbines, and a reduction from $\$ 3 / \mathrm{W}$ to $\$ 2 / \mathrm{W}$ doubles the economic potential for the residential sector again to just over $1 \mathrm{GW}$. The commercial class of turbines follows the same trajectory as the residential class, while the sum of all turbine classes follows the same trend as both classes, where the economic potential grows rapidly when prices decline below $\$ 3 / \mathrm{W}$. The decline in price has little effect on the larger sized systems, because these systems are already priced below $\$ 2 / \mathrm{W}$. The total economic potential in California reaches $4.4 \mathrm{GW}$ at prices of $\$ 2 / \mathrm{W}$ in 2020 .

The reduction in CAPEX is paramount for distributed wind to become increasingly competitive. For comparison, our ATB Mid Cost schedule prices the CAPEX of distributed solar at $\$ 2.30 / \mathrm{W}$ for the residential sector and $\$ 1.63 / \mathrm{W}$ for the commercial and industrial sectors in 2020. Even at $\$ 2 / \mathrm{W}$ for residential wind, the distributed wind economic potential of $4.4 \mathrm{GW}$ falls well below that of distributed solar $(37 \mathrm{GW})$, as underlying variables such as siting availability, load demand, and wind resource potential constrains further viability.

Further reductions in price are needed in the years after the federal investment tax credit expires. By 2030 , a price of $\$ 2 / \mathrm{W}$ results in a marginal increase in total economic potential, as it is driven by a growth in the residential class of turbines (Figure 14, next page). Economic potential only significantly grows when prices decline below $\$ 2 / \mathrm{W}$, due in large part to the forecast of continued cost reductions in solar. For example, in 2030, our ATB Mid Cost schedule prices the CAPEX of distributed solar at $\$ 1.49 / \mathrm{W}$ for the residential sector and $\$ 1.12 / \mathrm{W}$ for the commercial and industrial sectors.

For reference, the average cost of an 8.9-kW turbine deployed in 2017 was $\$ 10.76 / \mathrm{W}$ while the average for a $90-\mathrm{kW}$ turbine in 2017 was $\$ 4.67 / \mathrm{W}$ (Orrell 2018). To reach the $\$ 2 / \mathrm{W}$ target, CAPEX prices for the $8.9 \mathrm{~kW}$ turbine must decline $67 \%$ over a span of 13 years, or $12 \%$ annually. The $90-\mathrm{kW}$ turbine cost must decline $6 \%$ annually to reach $\$ 2 / \mathrm{W}$ in 2030 . See Appendix $\mathrm{C}$ for the values from this analysis. 


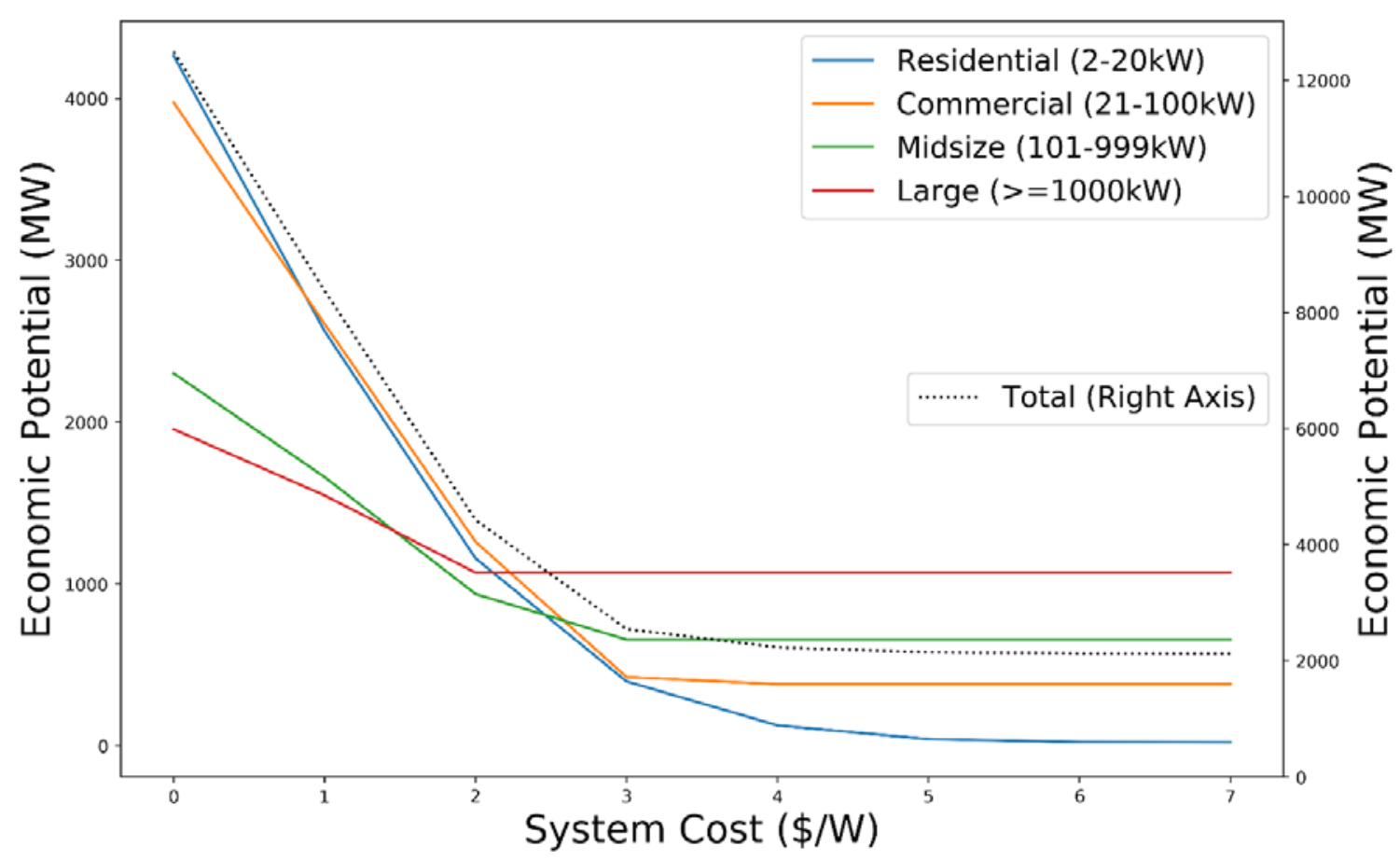

Figure 13. Economic potential of distributed wind versus system cost in 2020 by turbine class (left axis) and compiled as a total (right axis)

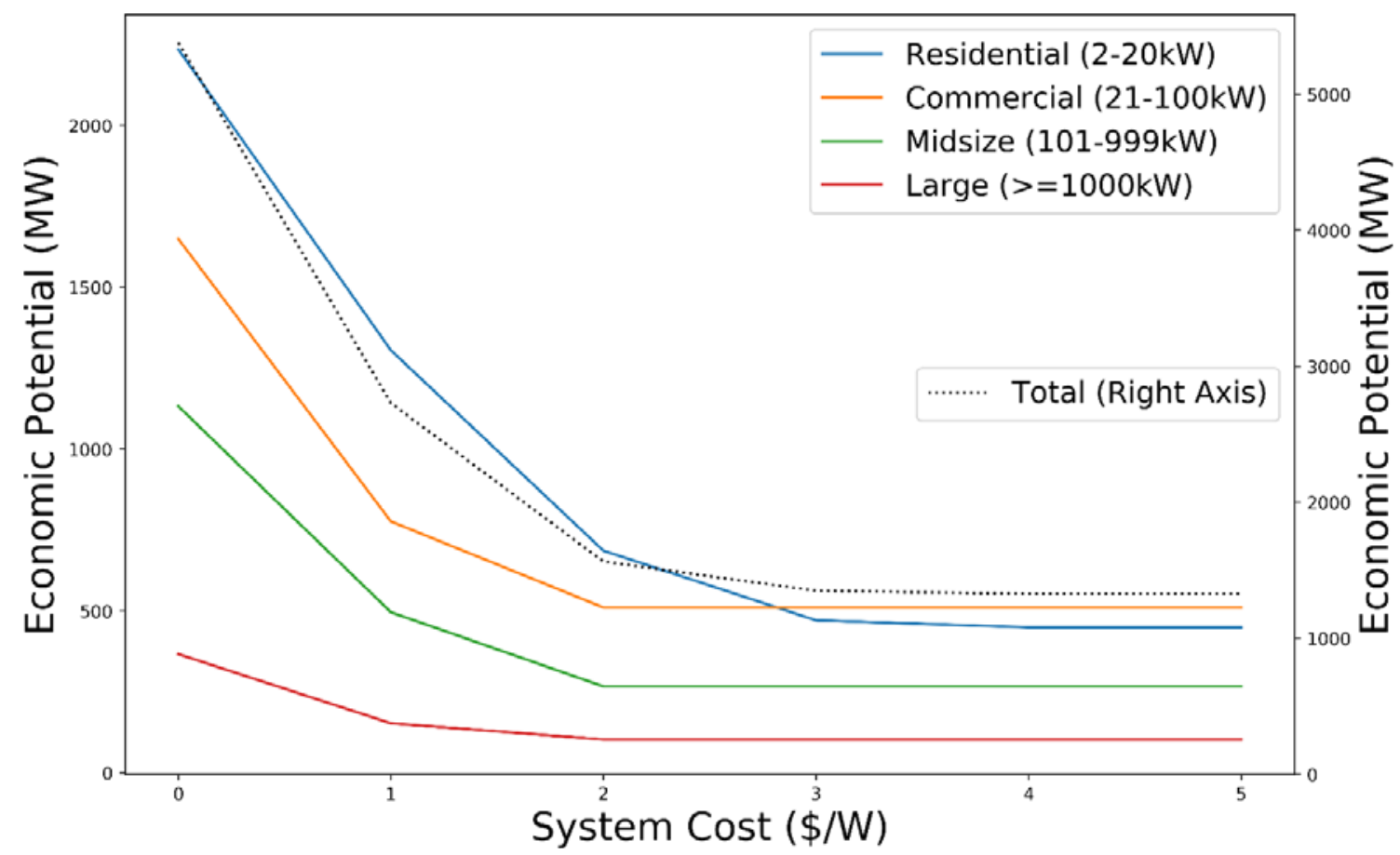

Figure 14. Economic potential of distributed wind versus system cost in 2030 by turbine class (left axis) and compiled as a total (right axis) 


\subsection{The Value of Distributed Wind and Distributed Solar Generation with Increased Variable Renewable Resource Penetration}

As deployment of utility-scale and distributed-scale wind and solar increases in California, the time-value of electricity, as realized through wholesale electricity prices, will continue to evolve to reflect the cost of supplying electricity. Most projections of capacity expansion indicate that a majority of the new renewable capacity will come from solar (Brinkman et al. 2016). In turn, electricity generation during periods of low solar irradiance - particularly during the late afternoon-evening ramp - increases in value (Mills 2016). We expect TOU periods to periodically adjust to better reflect the changing hours of peak pricing.

To understand the implications of increasing renewable penetration on long-term intertechnology competition, we examine changes in the value of residential wind generation and solar generation for three five-year intervals from 2020 to 2030. Our approach is to use modeled forecasts of California wholesale electricity prices and analyze how the evolution in wholesale prices would affect distributed wind and solar generation value if these were the price signals used to compensate DER systems. Specifically, the annual generation value of a residential wind system is estimated at the county level by taking the sum product of capacity factor at a $30-\mathrm{m}$ hub height and projected hourly wholesale electricity prices. This sum product is then normalized by the total annual capacity factor and multiplied by $10,000 \mathrm{kWh}$, to estimate the value of $10,000 \mathrm{kWh}$ of annual energy production from a distributed wind system in each county. The same value is calculated for solar using solar capacity factors and the same wholesale electricity prices. That is, the calculation is capacity-agnostic, as we are interested in the value of generation. Note that this is a hypothetical example and should not be interpreted as a forecast of future retail policy nor advocating for policy design.

\subsubsection{Value of Generation}

For this analysis, we incorporate a projection of hourly wholesale prices by balancing authority for 2020, 2025, and 2030. These wholesale prices are simulated outputs of the production cost model used in the California Low Carbon Grid Study (Brinkman et al. 2016), which were amended for this study to reflect a scenario in which California reaches $100 \%$ renewable energy generation by 2045. The installed solar and wind capacities (Table 5) reflect a least-cost capacity expansion to reach $100 \%$ renewable generation and all operational grid requirements. In this scenario, solar capacity is projected at $59.6 \mathrm{GW}$ and wind at $10.0 \mathrm{GW}$ in 2030.

Table 5. Projected Installed Capacity Upon Which the Hourly Wholesale Electricity Prices are Based

\begin{tabular}{|c|c|c|}
\hline Year & $\begin{array}{l}\text { Total Installed Solar } \\
\text { Capacity (MW) }\end{array}$ & $\begin{array}{l}\text { Total Installed Wind } \\
\text { Capacity (MW) }\end{array}$ \\
\hline 2020 & 31,863 & 6,292 \\
\hline 2025 & 47,868 & 6,512 \\
\hline 2030 & 59,598 & 10,036 \\
\hline
\end{tabular}


Based on the capacity expansion forecast used here, the value of residential wind generation tends to increase in most of California over time, largely as a function of increasing solar penetration. In Figure 15, we have mapped the relative value between solar generation and wind generation by county; the color scale represents how much more valuable $10,000 \mathrm{kWh}$ of generation from one technology is than the other in terms of dollars. As seen in this figure, the number of counties where distributed wind generation is more valuable that of distributed solar grows from 17 counties in 2020 to 22 counties by 2025. Four of these new counties emerge in Southern California and two counties arise in central California. Only one county in north central California switches from being more valuable for wind generation to more valuable for solar generation in 2025. In 2030, the new counties where distributed wind generation becomes more valuable surround the Bay Area, while Central California and Southern California remain strongholds for wind. Overall, 8 of the 40 counties that were more favorable for distributed solar generation in 2020 switch to being more favorable for distributed wind generation by 2030 . See Appendix D for the complete values of generation used to create Figure 15.
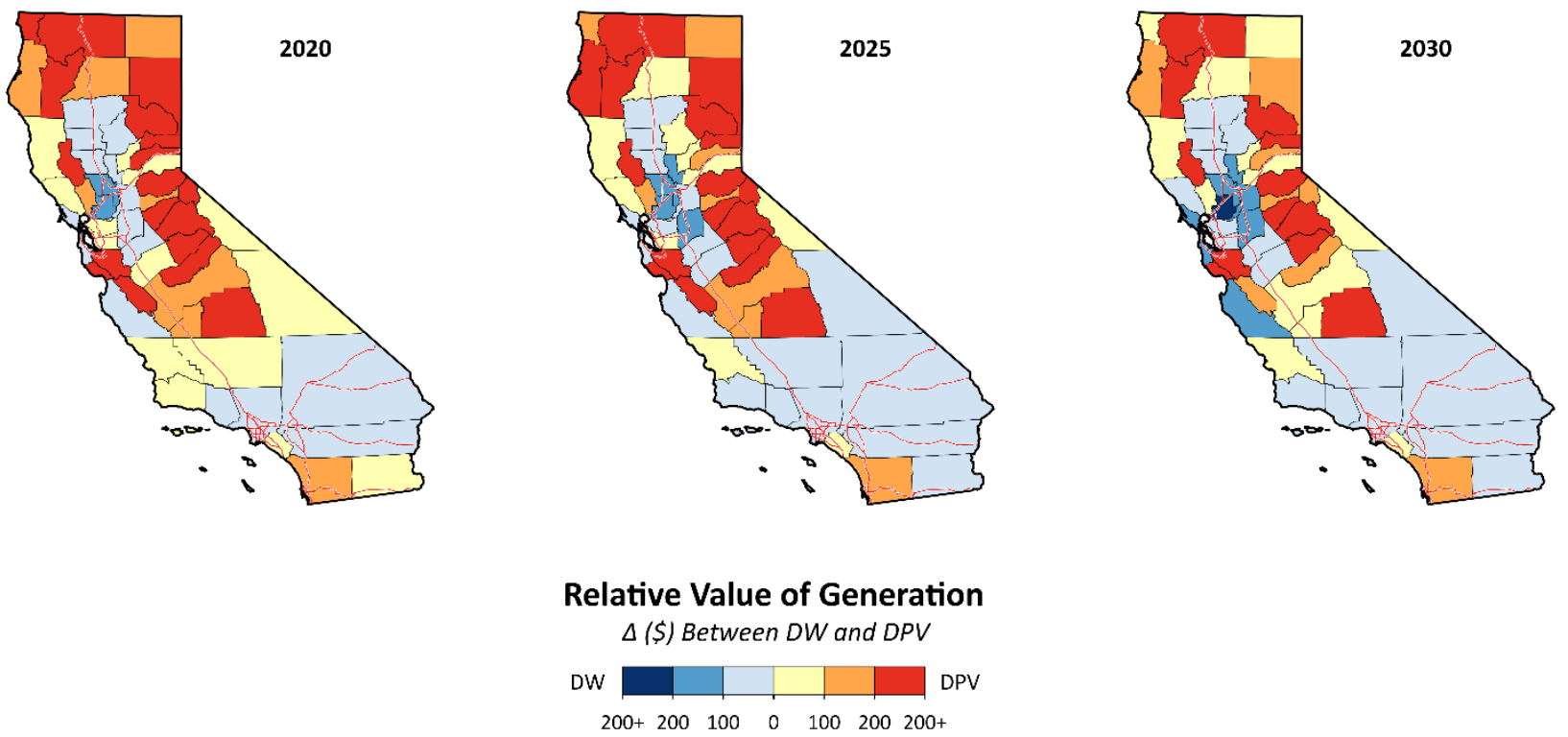

Figure 15. Difference between the value of wind generation and the value of solar generation, by county

DW = distributed wind, DPV = distributed solar photovoltaics

\subsubsection{Change in Value of Generation}

Most counties where residential solar energy is more valuable than wind energy in 2020 remain more valuable in 2030. However, though a unit of energy generated by solar remains more valuable than energy generated by wind in those counties, the shift from 2020 to 2030 improved the value of wind more positively than the value of solar in almost every county. Figure 16 illustrates the relative change in value of distributed wind generation and distributed solar generation from 2020 to 2025 and from 2020 to 2030, where the color scale represents the difference on a percentage basis. In almost all counties, the value of residential wind energy increases more than the value of residential solar energy as solar penetration increases. Residential solar generation only increased in value relative to wind in Los Angeles County and 
Tuolumne County in 2030. See Appendix E for the percentage change in value from 2020 by technology that was used to create Figure 16.
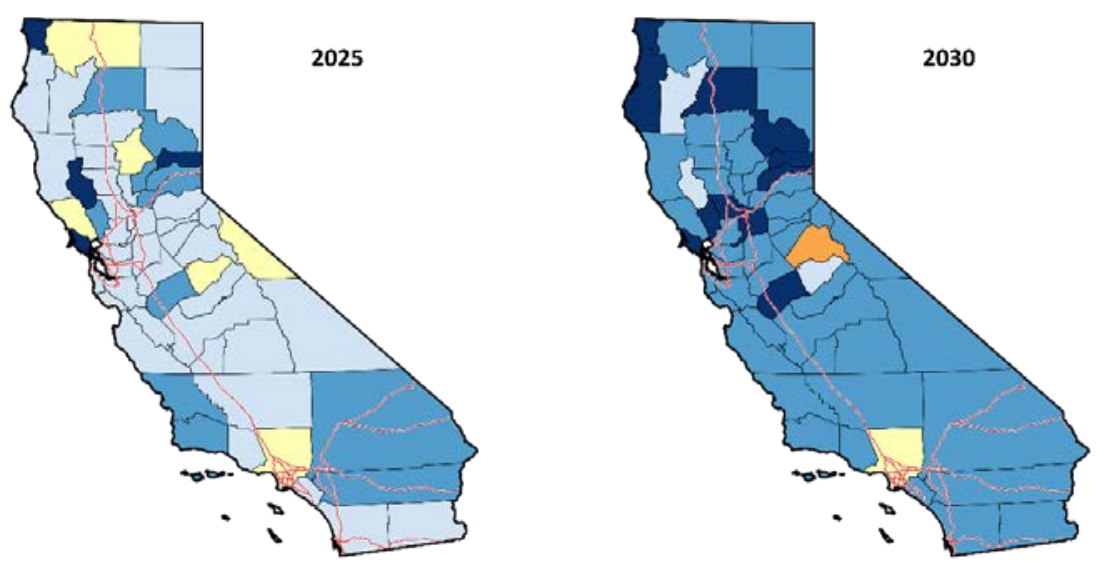

Change in Value of Generation From 2020

$\triangle(\%$ Change From 2020) Between DW and DPV

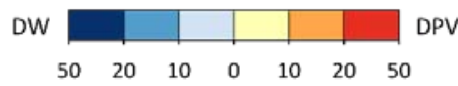

Figure 16. Difference between the percentage change in generation value from 2020 of solar and wind

\subsection{Geospatial Trends in Distributed Generation Potential}

McCabe et al. 2018 have demonstrated the close relationship of the economic viability of distributed wind and several key geospatial factors. In particular, data layers that represent the wind resource, end-use load, and siting availability all contribute to inform areas of elevated economic potential within a given state or region. Unique to our analysis, is the competition aspect of two distributed generation technologies: distributed wind and distributed solar. In this section, we examine the effect of each of these layers on the economic viability of distributed wind and solar specifically in California.

The estimates of economic potential represent the amount of distributed wind capacity that could be deployed at a positive NPV (calculated over the life of the facility) in a given year, using a weighted average cost of capital of $5.4 \%$ in each scenario. In addition, these estimates exclude parcels that do not conform to the siting restrictions applied in each scenario and are limited to the amount of on-site electrical load. Though previous sections have shown the time-dependent nature of economic potential - including the effects of changing capital costs, load growth, expiration of policies and incentives, and escalation of retail rate prices - the heat maps ${ }^{9}$ in subsequent sections show the potential for a static moment in time. Unless otherwise noted, 2030 is used as the default analysis period.

\footnotetext{
${ }^{9}$ Borrowing from the precedent set by McCabe et al. (2018), these maps are colloquially referred to as heat maps, though the more accurate description would be choropleth maps.
} 


\subsubsection{Economic Potential}

For the TOU Baseline scenario, the aggregate statewide amount (i.e., all sectors and turbine classes) of distributed wind economic potential in 2030 is just over 1,300 MW. Conversely, the aggregate statewide amount of distributed solar economic potential in the same year is just over 44,000 MW. Figure 17 summarizes the 2030 economic potential results at the county level.
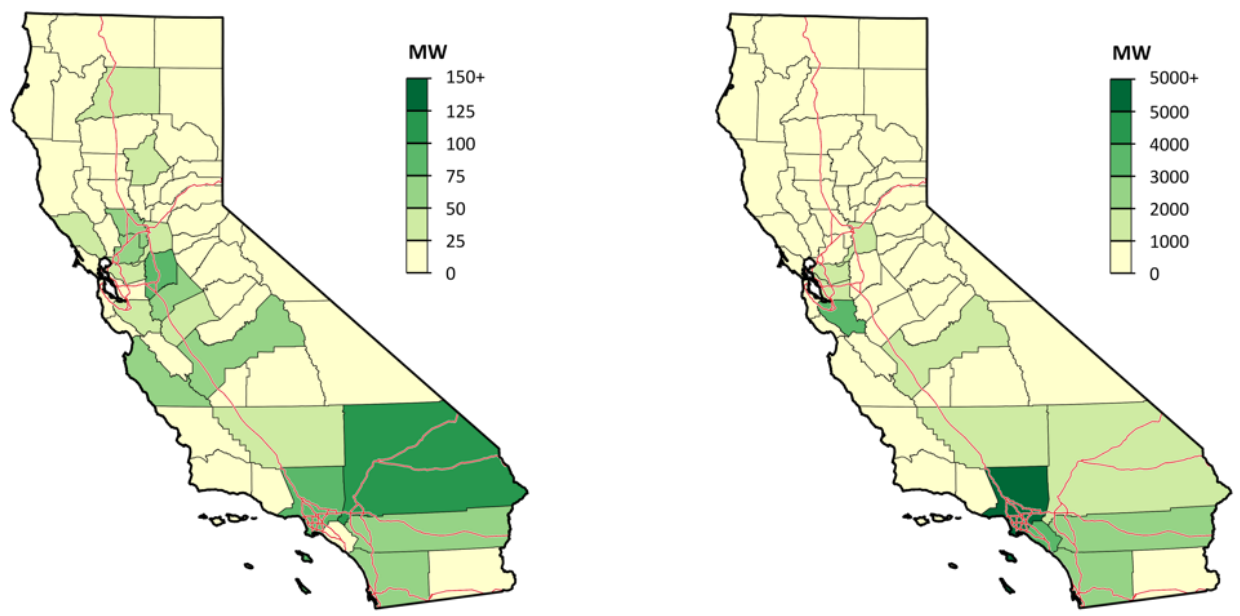

Figure 17. Total (all sectors and turbine classes) economic potential (MW) in $\mathbf{2 0 3 0}$ for the TOU Baseline scenario-wind (left) and solar (right)

Note the difference in scale values.

\subsubsection{Wind Resource}

The state-level resource (Figure 18) informs the ultimate amount of distributed generation economic potential in California. However, when considered independently, resource alone is not necessarily a strong indicator of the economic viability of a distributed generation projectother geospatial factors contribute to the final estimate of economic potential in a given county. However, from a state-level perspective, the disparity between the overall resource strength for distributed wind and distributed solar in California appears to strongly correlate with the total economic potential for each technology. Figures 18 and 19 show the state-level resource map for each technology: direct normal solar irradiance (DNI; $\mathrm{kWh} / \mathrm{m}^{2} /$ day) for solar and wind speed $(\mathrm{m} / \mathrm{s})$ at $80 \mathrm{~m}$ and $30 \mathrm{~m}$. The figures show a larger degree of spatial variance in wind resource than in solar resource in the state. 

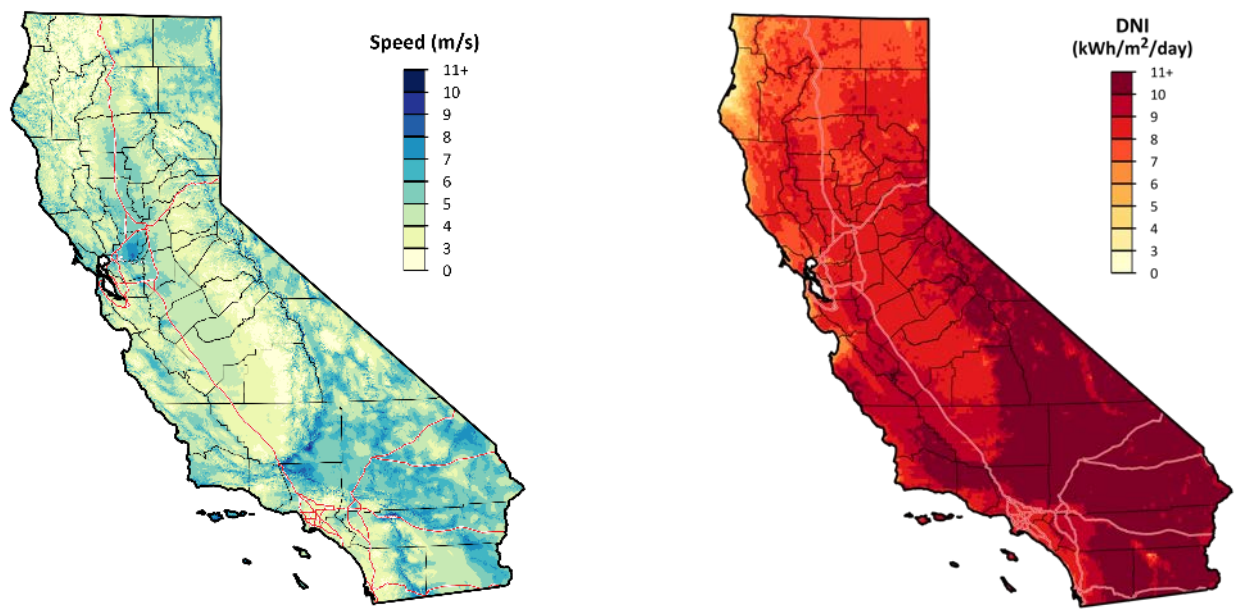

Figure 18. Average wind speed $(\mathrm{m} / \mathrm{s})$ at 80 -meter hub height in (left) and DNI (kWh/m²/day) (right)

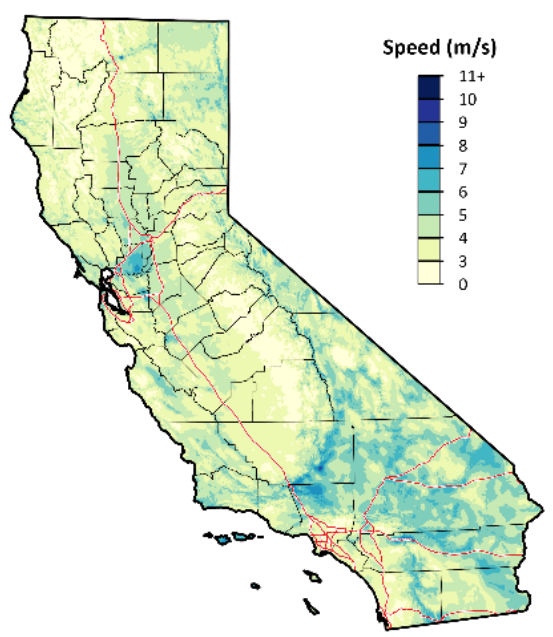

Figure 19. Average wind speed $(\mathrm{m} / \mathrm{s})$ at 30 -meter hub height

\subsubsection{Electrical Load}

The relationship between electrical load and economic potential is fairly straightforward in that distributed generation technologies are deployed proportionately to on-site energy consumption. The amount of load in each county in California reflects both the number of customers (i.e., residential homes, commercial buildings, or industrial sites) and the per capita energy usage of each customer. Though the electrical load is technology-agnostic, the county-level map demonstrates a strong spatial correlation not only with known population centers in the state but also with the amount of economic potential for both distributed wind and solar. Figure 20 shows the map of electrical load by county in 2030 . 


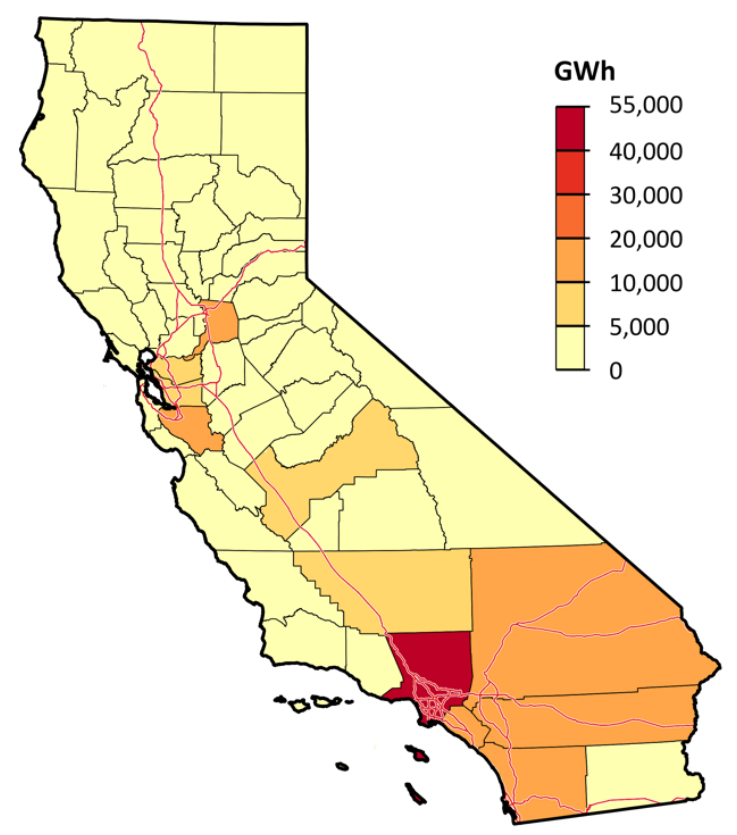

Figure 20. Projected annual electricity consumption (GWh) for all (residential, commercial, and industrial) customers in $\mathbf{2 0 3 0}$

Major metropolitan centers in California include areas collocated with the cities of Los Angeles, Riverside, San Bernardino, and San Diego in Southern California; Fresno in the San Joaquin Valley; and Sacramento, San Francisco, Oakland, and San Jose in Northern California. Each of these areas correlates with counties of higher electrical load as depicted in Figure 20, including Los Angeles County, San Bernardino County, Fresno County, Santa Clara County, and Sacramento County, among others. In many cases, these exact counties exist as areas of elevated economic potential as shown in Figure 20, which demonstrates the strong linkage between the two data layers.

\subsubsection{Siting Availability}

Though load and resource inform areas of increased favorability for distributed generation technologies, site-level exclusions can limit potential project development and therefore economic potential. Figure 21 provides visualizations of the siting availability for both distributed wind and solar. As discussed in McCabe et al. (2018), we simulate siting restrictions via two proxy variables: the average parcel area as a proxy for turbine setback from property lines and the level of tree canopy cover. Figure 21 (next page) shows the percentage of all turbine configurations considered in dGen that could be sited in a given parcel (i.e., unique combinations of turbine capacities and hub heights). Lower values represent either areas where siting constraints could prohibit development or areas in which no buildings exist.

A similar visualization was created to show an equivalent metric for distributed solar, though there are differences in the metrics. Siting limitations for solar are mostly defined by the suitability of the rooftop and are typically less stringent than those for distributed wind. Figure 21 shows the modeled siting availability for solar, which is defined as the proportion of "solar- 
suitable" ${ }^{10}$ buildings to the total building count for each census tract. Importantly, solar siting availability shares a key characteristic with wind siting availability, in that areas with no buildings are represented as unsuitable (e.g., $0 \%$ siting availability).
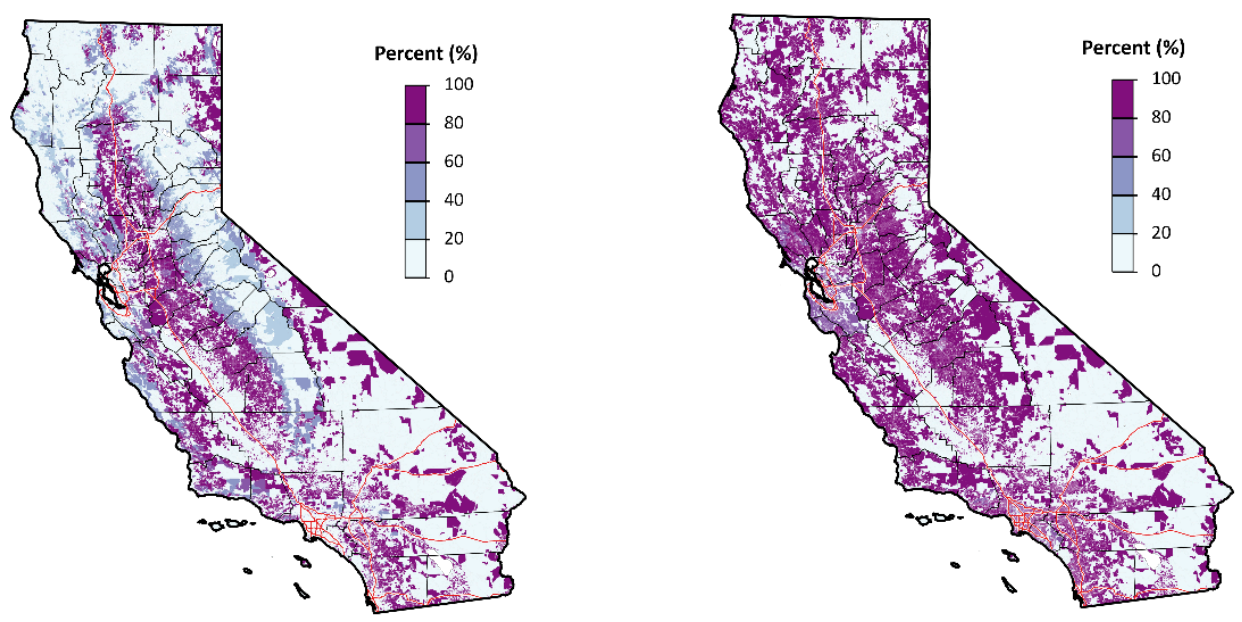

Figure 21. Favorability for siting availability for wind (left) and solar (right)

Wind siting availability is represented by the proportion of the total number of turbine configurations available for siting at each parcel and solar siting availability by the total portion of "solar-suitable" buildings relative to the total building count for each census tract.

For distributed solar projects, the siting constraints have very little effect on the favorability for siting in nearly all parts of the state. We see lower percentages of the siting availability metric in only (1) areas with high concentrations of commercial or industrial sites and (2) highly dense urban areas in which the roof characteristics themselves (e.g., overly shaded, non-southward facing, area-limited) prohibit extensive development. Figure 22 represents a subset of the solar siting availability map in Figure 21, in which the broader Bay Area is shown-the tip of the San Francisco Peninsula, an area of high building density, shows lower values of solar siting availability.

For distributed wind projects, similar trends can be seen in areas of high population density-in particular, the major metropolitan regions named in Section 3.3.3. However, the map of siting availability for distributed wind statewide shows much more nuance and considers the morestringent aspects of siting wind projects on parcels that may be area-limited or canopy coverlimited - including areas that may exist outside those with a high population density. Conversely, parts of the state that are considered to have more area for development (i.e., larger parcel sizes) show greater availability for siting wind projects. These trends are reflected in the maps of economic potential for each distributed generation technology, where the economic potential of solar more closely follows areas of higher load with little restriction and the economic potential of wind is limited in areas of high population density and therefore low siting availability.

\footnotetext{
${ }^{10}$ See Sigrin and Mooney 2018 for a discussion of solar suitability.
} 


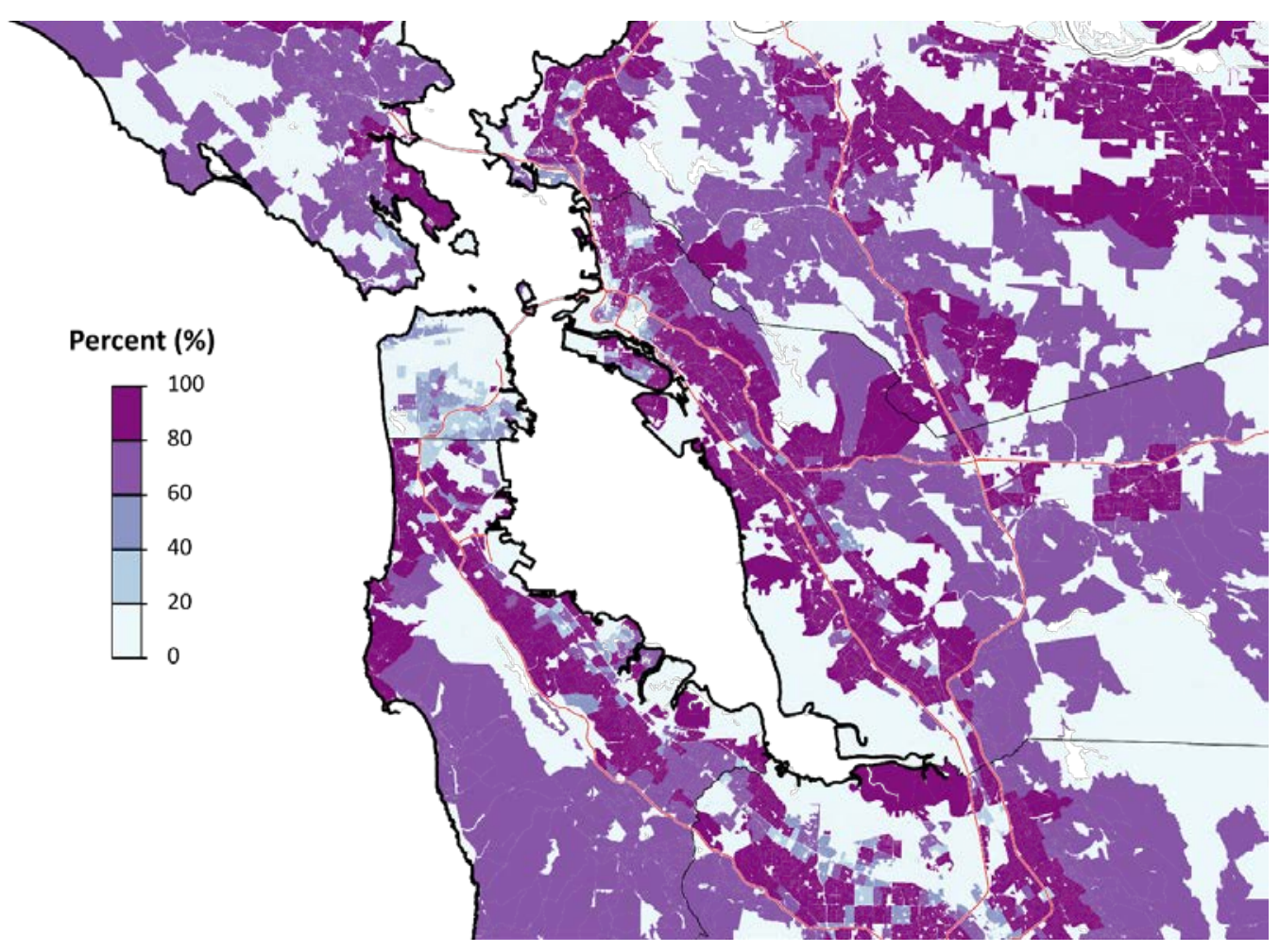

Figure 22. Map of tract-level solar siting availability for the southern and eastern Bay Area

\subsubsection{Effects of Capital Cost Reductions on Distributed Generation Potential}

While the preceding sections highlight the intricate relationship between key geospatial layers and the economic potential of distributed generation technologies, Section 3.2 more broadly described the positive effect of a non-geospatial trend - the reduction of capital costs. Adding the effect of reduced costs as an additional "layer," we can discern other geospatial trends in the viability of distributed wind. In particular, reducing capital costs allows us to visualize which areas in the state can be "unlocked" and could see an increase in distributed wind viability. Figure 23 shows the incremental change in economic potential relative to the TOU Baseline scenario for an increased competitiveness scenario (TOU High Cost Solar) and two reduced cost scenarios $(\$ 1 / \mathrm{W}$ and $\$ 0 / \mathrm{W})$. 

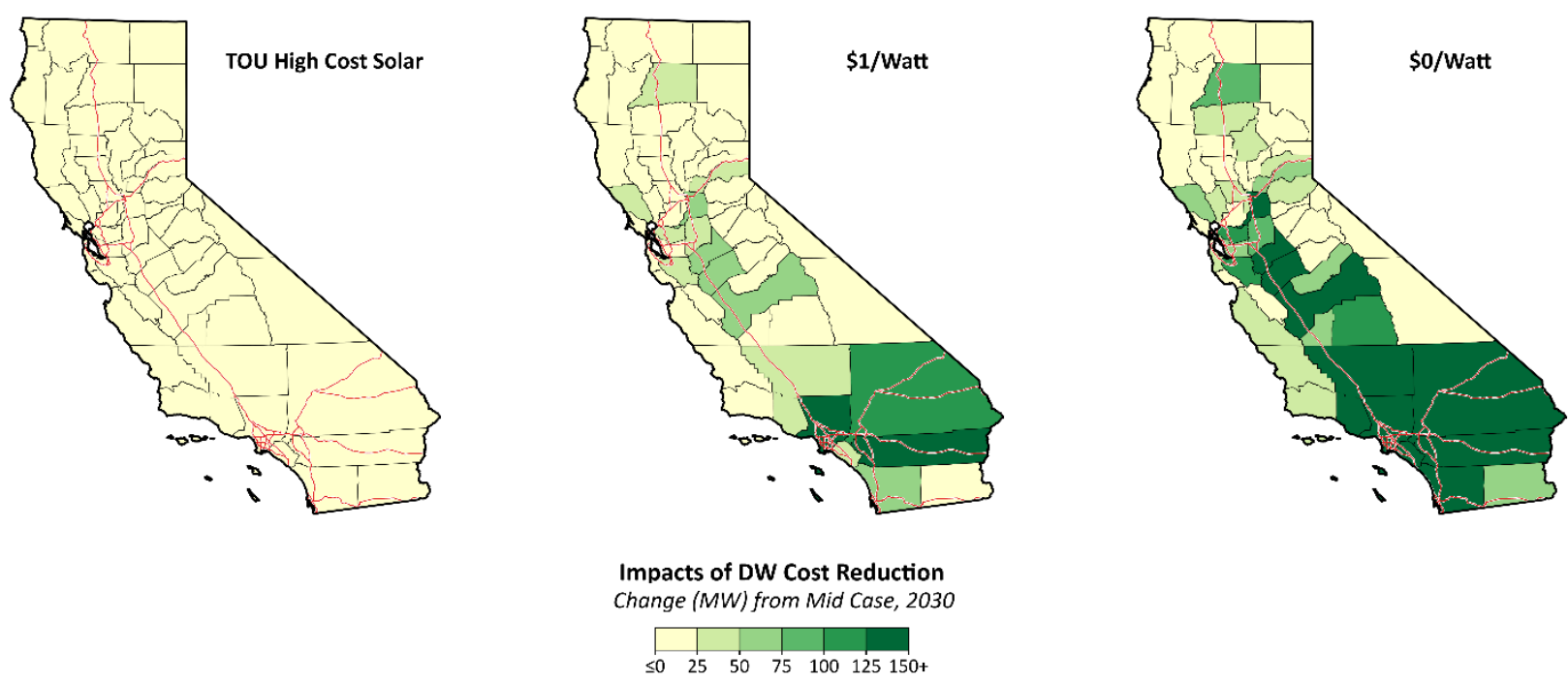

Figure 23. Change in economic potential relative to the TOU Baseline scenario results for the TOU High Cost Solar scenario (left), \$1/W scenario (middle), and \$0/W scenario (right)

In the TOU High Cost Solar scenario, where distributed wind costs remain the same but distributed solar costs are higher than in the Baseline case, there is very little incremental change in the economic potential statewide. This result indicates that solar capital costs are already low enough that a 35\% markup from the Mid cost schedule does not improve wind's economic competitiveness. However, as we decrease wind to cost targets that solar has traditionally adopted (e.g., $\$ 1 / \mathrm{W}$ ), the economic viability of wind increases dramatically. In the $\$ 1 / \mathrm{W}$ scenario, several of the counties that showed elevated potential in the Mid case more than double in value. And in the hypothetical bounding case of $\$ 0 / \mathrm{W}$ wind, many more counties show similar increases and new counties are introduced into higher tiers of economic potential. We include this scenario for better understanding of the maximum potential of counties in California, less the effects of any operation and maintenance costs, poor wind resource, small electrical load, and unavailable siting conditions. 


\section{Conclusion}

In this analysis, we studied the relative competitiveness of DER technologies in California through three topics: the implications of TOU retail tariffs on the economic potential of behindthe-meter distributed wind and solar through 2030, the level of cost improvement needed for a competitive distributed wind market, and the regions and sectors where distributed wind is already competitive or is emerging as competitive.

Comparing our Baseline scenario (current non-mandatory TOU rates) to our TOU Baseline scenario, our results show that extending TOU rates to all residential customers decreases the economic viability of distributed wind in California. Though the commercial and industrial sectors remain the same because of their existing TOU rate requirement, cumulative distributed wind economic potential for the residential sector in 2030 decreases by $150 \mathrm{MW}$, from roughly $550 \mathrm{MW}$ of economic potential with the current tiered rate structure to just over $400 \mathrm{MW}$ with TOU. The economic potential of all sectors decreases from just under $1.5 \mathrm{GW}$ with tiered rates to a little over $1.3 \mathrm{MW}$ with TOU rates in 2030 . We attribute this dip in performance to the mismatch between TOU peak periods and wind's performance throughout the day. Though TOU tariffs decrease distributed wind economic potential, our model equates the $1.3 \mathrm{GW}$ of potential to over 80,000 economically viable distributed wind projects. Distributed solar improves from a total of $43 \mathrm{GW}$ of economic potential in 2030 with tiered rates to roughly $44 \mathrm{GW}$ under TOU implementation as a result of stronger overlap between peak periods and production.

Though distributed solar demonstrates greater economic potential than distributed wind, residential wind generation gains more value than solar generation as increased solar penetration alters the time value of electricity generation. Counties around the Bay Area and in Southern California emerge as places where wind generation has a higher value than solar generation as solar penetration increases. Furthermore, even in counties where solar generation remains more valuable, the change in value of residential wind generation is higher than the change in value of residential solar generation by 2030 in all but two counties.

For distributed wind to become competitive with distributed solar, CAPEX for wind must continue to fall. System costs must fall below $\$ 3 / \mathrm{W}$ by 2030 for wind to gain in economic competitiveness, but a reduction to below $\$ 2 / \mathrm{W}$ is needed to increase the economic potential significantly. Another barrier to distributed wind's growth is the continuing decline in distributed solar prices, which are at less than $\$ 1.50 / \mathrm{W}$ by 2030 in our model.

Under our TOU Baseline scenario, the counties in California that exhibit the most distributed wind economic potential in 2030 lie in Southern California, namely San Bernardino County and Los Angeles County. Another pocket of elevated potential exists in counties east of the San Francisco Bay and at the northern tip of the San Joaquin Valley. Distributed solar exhibits highest economic potential in similar regions as distributed wind, including much of Southern California and counties south and east of the Bay Area.

Several geospatial factors feed into the economic viability of distributed generation technologies, namely resource potential, electrical load, and siting availability. The overall higher resource potential for distributed solar manifests itself in its thirty-fold larger economic potential than distributed wind. Distributed wind also faces much higher siting constraints, mainly because of 
high population density, property area limits, and canopy cover. In general, counties with high electrical load emerge as counties with the highest economic potential for both technologies.

Though our study offers an in-depth analysis of distributed wind economic potential in California, opportunities for further work exist to improve the accuracy of our results. Improvements to the underlying data include more-resolved load shape data for all utilities, more-detailed insight into future TOU tariff structures for when all sectors are on default TOU rates, and new wind power curves and wind resource data to represent the latest distributed wind turbine technology. Improvements to our method of assigning rates to customers are also needed. Our model has uniform rates for all customers within a utility, and it assigns a customer to a utility based on who serves their geographical location. But the major investor-owned utilities also have unique prices and baseline allowances for each geographical service region within the utility. Adding such a layer of geographical resolution would allow us to more-accurately represent the price of electricity for all customers in varying locations. In addition to the improvements in our input data, assessing the opportunity of front-of-the-meter distributed wind could further illuminate the economic potential of distributed wind in California. 


\section{References}

Barbose Galen, and Naïm Darghouth. 2018. Tracking the Sun: Installed Price Trends for Distributed Photovoltaic Systems in the United States, 2018 Edition. https://emp.lbl.gov/sites/default/files/tracking the sun_2018 edition_final_0.pdf.

Brinkman, Gregory, Jennie Jorgenson, Ali Ehlen, and James H. Caldwell. 2016. Low Carbon Grid Study: Analysis of a 50\% Emission Reduction in California. NREL/TP-6A20-64884. Golden, CO: National Renewable Energy Laboratory. https://doi.org/10.2172/1235548.

Cole, Wesley, Will Frazier, Paul Donohoo-Vallett, Trieu Mai, and Paritosh Das. 2018. 2018 Standard Scenarios Report: A U.S. Electricity Sector Outlook. NREL/TP-6A2071913. Golden, CO: National Renewable Energy Laboratory. https://doi.org/10.2172/1481848.

CPUC (California Public Utility Commission). 2018. "Residential Rate Reform: R.12-06-013." Accessed December 15, 2018: http://www.cpuc.ca.gov/General.aspx?id=12154.

CSBOE (California State Board of Equalization). 2008. Solar Energy Property Tax Incentive. 2008/037. May 21, 2008. https://www.boe.ca.gov/proptaxes/pdf/lta08037.pdf.

Darghouth, Naïm R., Ryan H. Wiser, Galen Barbose, and Andrew D. Mills. 2016. "Net Metering and Market Feedback Loops: Exploring the Impact of Retail Rate Design on Distributed PV Deployment." Applied Energy 162: 713-722. https://doi.org/10.1016/j.apenergy.2015.10.120.

Denholm, Paul, Matthew O'Connell, Gregory Brinkman, and Jennie Jorgenson. 2015. Overgeneration from Solar Energy in California. A Field Guide to the Duck Chart. NREL/TP-6A20-65023. Golden, CO: National Renewable Energy Laboratory. https://doi.org/10.2172/1226167.

Denholm, Paul, Kara Clark, and Matt O'Connell. 2016. On the Path to SunShot: Emerging Issues and Challenges in Integrating High Levels of Solar into the Electrical Generation and Transmission System. Golden, CO: National Renewable Energy Laboratory. NREL/TP-6A2065800. https://doi.org/10.2172/1253978.

Folkman, Jim, Khlement Hodge, Elizabeth Hutchison, and Katharine Larson. 2016. Implementation of Small Wind System Ordinances by California Counties. CEC-300-2016-001. California Energy Commission. https://www.energy.ca.gov/2016publications/CEC-300-2016001/CEC-300-2016-001.pdf.

Gagnon, Pieter, Robert Margolis, Jennifer Melius, Caleb Phillips, and Ryan Elmore. 2016. Rooftop Solar Photovoltaic Technical Potential in the United States: A Detailed Assessment. Golden, CO: National Renewable Energy Laboratory. NREL/TP-6A20-65298. https://doi.org/10.2172/1236153.

Go Solar California. n.d. "History of Solar Energy in California." Accessed December 15, 2018: https://www.gosolarcalifornia.ca.gov/about/gosolar/california.php. 
Lantz, Eric, Benjamin Sigrin, Michael Gleason, Robert Preus, and Ian Baring-Gould. 2016. Assessing the Future of Distributed Wind: Opportunities for Behind-the-Meter Projects. NREL/TP-6A20-67337. Golden, CO: National Renewable Energy Laboratory. https://doi.org/10.2172/1333625.

McCabe, Kevin, Benjamin Sigrin, Eric Lantz, and Meghan Mooney. 2018. Assessment of the Economic Potential of Distributed Wind in Colorado, Minnesota, and New York. NREL/TP6A20-70547. Golden, CO: National Renewable Energy Laboratory. https://doi.org/10.2172/1419628.

Mills, Andrew. 2016. "Impact of Price-Responsive Demand on the Value of PV." Berkeley, CA: Laboratory Lawrence Berkeley National Laboratory. In Kurtz, Sarah, and Michael Bolen. Retaining the Value of PV at High Penetration Workshop. PR-5J00-67467. Golden, CO: National Renewable Energy Laboratory. https:/www.nrel.gov/docs/fy17osti/67467.pdf

Mills, Andrew, and Ryan Wiser. 2012. An Evaluation of Solar Valuation Methods Used in Utility Planning and Procurement Processes. Berkeley, CA: Laboratory Lawrence Berkeley National Laboratory. LBNL-5933E. https://emp.lbl.gov/sites/all/files/lbnl-5933e.pdf.

Mooney, Meghan, and Sigrin, Ben. Rooftop Energy Potential of Low-Income Communities in America REPLICA. United States. https://doi.org/10.7799/1432837.

NREL (National Renewable Energy Laboratory). 2018. "2018 Annual Technology Baseline.” Golden, CO: National Renewable Energy Laboratory. https://atb.nrel.gov/.

OpenEI. 2014. U.S. Utility Rate Database. Accessed December 15, 2018 : http://en.openei.org/wiki/Utility Rate_Database.

Orrell, Alice, Nik Foster, Scott Morris, Juliet Homer, Danielle Preziuso, and Eric Poehlman. 2018. 2017 Distributed Wind Market Report. DOE/EE-1799. Pacific Northwest National Laboratory. https://www.energy.gov/sites/prod/files/2018/09/f55/2017-DWMR-091918final.pdf.

Sigrin, Benjamin, Michael Gleason, Robert Preus, Ian Baring-Gould, and Robert Margolis. 2016. Distributed Generation Market Demand Model (dGen): Documentation. NREL/TP-6A2065231. Golden, CO: National Renewable Energy Laboratory. https://doi.org/10.2172/1239054.

Wood Mackenzie. 2018. U.S. Solar Market Insight Q4 2018: Full Report. December 2018. 


\section{Appendix A. Economic Potential Results}

Table A-1. Economic Potential Results by Technology and Scenario (MW)

\begin{tabular}{|c|c|c|c|c|c|c|c|c|c|c|c|c|}
\hline \multirow[b]{2}{*}{ Year } & \multicolumn{2}{|c|}{ Baseline } & \multicolumn{2}{|c|}{ TOU Baseline } & \multicolumn{2}{|c|}{ High Cost Wind } & \multicolumn{2}{|c|}{ TOU High Cost Wind } & \multicolumn{2}{|c|}{ TOU High Cost Solar } & \multicolumn{2}{|c|}{ TOU Low Cost Solar } \\
\hline & Wind & Solar & Wind & Solar & Wind & Solar & Wind & Solar & Wind & Solar & Wind & Solar \\
\hline 2018 & $2,144.1$ & $38,622.1$ & $2,144.1$ & $38,622.1$ & 856.7 & $39,057.5$ & 856.7 & $39,057.5$ & $2,243.1$ & $36,654.3$ & $1,832.6$ & $40,324.9$ \\
\hline 2019 & $2,480.0$ & $38,510.1$ & $2,470.7$ & $38,719.7$ & 990.4 & $39,043.9$ & 994.0 & $39,242.8$ & $2,550.5$ & $36,205.1$ & $2,047.3$ & $40,731.7$ \\
\hline 2020 & $2,044.0$ & $39,324.5$ & $2,026.9$ & $39,497.6$ & 463.6 & $39,958.4$ & 467.7 & $40,108.5$ & $2,086.8$ & $37,342.2$ & $1,654.1$ & $41,145.5$ \\
\hline 2021 & 176.3 & $41,572.4$ & 170.7 & $41,996.9$ & 30.5 & $41,668.1$ & 31.4 & $42,081.1$ & 177.0 & $40,027.7$ & 146.8 & $44,059.5$ \\
\hline 2022 & 316.1 & $41,044.9$ & 289.0 & $41,486.3$ & 51.6 & $41,219.6$ & 53.9 & $41,636.0$ & 307.1 & $39,211.0$ & 249.1 & $43,706.8$ \\
\hline 2023 & 424.4 & $41,423.7$ & 386.0 & $41,991.1$ & 63.3 & $41,668.3$ & 66.7 & $42,210.7$ & 406.6 & $39,900.4$ & 336.0 & $44,163.9$ \\
\hline 2024 & 532.2 & $40,778.3$ & 482.7 & $41,333.4$ & 71.7 & $41,086.8$ & 73.9 & $41,613.6$ & 519.5 & $39,252.8$ & 418.4 & $43,477.7$ \\
\hline 2025 & 903.8 & $41,869.8$ & 819.7 & $42,340.0$ & 134.7 & $42,403.8$ & 129.3 & $42,842.3$ & 864.9 & $40,628.6$ & 716.7 & $44,562.2$ \\
\hline 2026 & $1,022.4$ & $42,018.8$ & 934.0 & $42,453.6$ & 164.7 & $42,635.3$ & 158.0 & $43,037.0$ & 985.9 & $40,840.5$ & 819.1 & $44,789.9$ \\
\hline 2027 & $1,067.8$ & $41,967.3$ & 961.0 & $42,505.6$ & 170.1 & $42,617.1$ & 159.8 & $43,113.3$ & $1,018.4$ & $40,967.4$ & 844.3 & $45,056.4$ \\
\hline 2028 & $1,123.2$ & $42,187.5$ & $1,021.3$ & $42,805.8$ & 195.6 & $42,878.9$ & 180.4 & $43,457.1$ & $1,081.6$ & $41,197.3$ & 899.0 & $45,422.9$ \\
\hline 2029 & $1,300.8$ & $42,734.2$ & $1,182.9$ & $43,405.7$ & 239.2 & $43,536.1$ & 218.3 & $44,161.8$ & $1,245.4$ & $41,800.7$ & $1,047.2$ & $46,099.7$ \\
\hline 2030 & $1,463.5$ & $43,383.3$ & $1,326.4$ & $44,039.6$ & 282.7 & $44,299.5$ & 257.6 & $44,900.6$ & $1,385.6$ & $42,355.1$ & $1,187.9$ & $46,639.8$ \\
\hline
\end{tabular}




\section{Appendix B. Distributed Wind Capital Costs}

Table B-1. Distributed Wind Capital Costs by Cost Scenario for the Baseline Scenario (\$/kW)

\begin{tabular}{|c|c|c|c|c|c|c|c|c|c|c|c|}
\hline YearlkW & 2.5 & 5 & 10 & 20 & 50 & 100 & 250 & 500 & 750 & 1,000 & $1,500+$ \\
\hline 2018 & $8,117.55$ & $6,683.15$ & $5,669.30$ & $4,952.46$ & $3,884.77$ & $3,594.93$ & $2,956.80$ & $2,673.65$ & $2,508.49$ & $1,653.26$ & $1,533.51$ \\
\hline 2019 & $7,582.54$ & $6,239.44$ & $5,290.11$ & $4,618.89$ & $3,567.83$ & $3,300.06$ & $2,714.91$ & $2,452.94$ & $2,300.12$ & $1,636.10$ & $1,517.47$ \\
\hline 2020 & $7,003.92$ & $5,759.54$ & $4,879.99$ & $4,258.12$ & $3,231.14$ & $2,986.85$ & $2,456.95$ & $2,217.62$ & $2,078.00$ & $1,619.54$ & $1,502.03$ \\
\hline 2021 & $6,585.66$ & $5,412.68$ & $4,583.60$ & $3,997.41$ & $2,976.41$ & $2,749.96$ & $2,262.24$ & $2,040.07$ & $1,910.47$ & $1,603.59$ & $1,487.19$ \\
\hline 2022 & $6,127.92$ & $5,033.07$ & $4,259.22$ & $3,712.07$ & $2,709.44$ & $2,501.70$ & $2,057.29$ & $1,853.22$ & $1,734.18$ & $1,588.25$ & $1,472.96$ \\
\hline 2023 & $5,629.69$ & $4,619.88$ & $3,906.12$ & $3,401.46$ & $2,432.34$ & $2,244.03$ & $1,843.72$ & $1,658.52$ & $1,573.55$ & $1,573.55$ & $1,459.34$ \\
\hline 2024 & $5,091.51$ & $4,173.53$ & $3,524.69$ & $3,065.92$ & $2,147.09$ & $1,978.79$ & $1,623.07$ & $1,559.47$ & $1,559.47$ & $1,559.47$ & $1,446.31$ \\
\hline 2025 & $4,515.23$ & $3,695.58$ & $3,116.23$ & $2,706.60$ & $1,855.50$ & $1,707.65$ & $1,546.04$ & $1,546.04$ & $1,546.04$ & $1,546.04$ & $1,433.90$ \\
\hline 2026 & $4,323.56$ & $3,536.71$ & $2,980.54$ & $2,587.31$ & $1,742.22$ & $1,602.45$ & $1,533.26$ & $1,533.26$ & $1,533.26$ & $1,533.26$ & $1,422.08$ \\
\hline 2027 & $4,113.58$ & $3,362.65$ & $2,831.87$ & $2,456.59$ & $1,626.19$ & $1,521.12$ & $1,521.12$ & $1,521.12$ & $1,521.12$ & $1,521.12$ & $1,410.87$ \\
\hline 2028 & $3,886.86$ & $3,174.69$ & $2,671.32$ & $2,315.42$ & $1,509.63$ & $1,509.63$ & $1,509.63$ & $1,509.63$ & $1,509.63$ & $1,509.63$ & $1,400.27$ \\
\hline 2029 & $3,645.19$ & $2,974.34$ & $2,500.18$ & $2,164.92$ & $1,498.80$ & $1,498.80$ & $1,498.80$ & $1,498.80$ & $1,498.80$ & $1,498.80$ & $1,390.26$ \\
\hline 2030 & $3,390.50$ & $2,763.19$ & $2,319.79$ & $2,006.29$ & $1,488.62$ & $1,488.62$ & $1,488.62$ & $1,488.62$ & $1,488.62$ & $1,488.62$ & $1,380.87$ \\
\hline
\end{tabular}


Table B-2. Distributed Wind Capital Costs by Cost Scenario for the High Scenario (\$/kW)

\begin{tabular}{|c|c|c|c|c|c|c|c|c|c|c|c|}
\hline YearlkW & 2.5 & 5 & 10 & 20 & 50 & 100 & 250 & 500 & 750 & 1,000 & $1,500+$ \\
\hline 2018 & $10,792.17$ & 8,893.03 & $7,550.68$ & $6,601.58$ & $5,387.50$ & $4,988.86$ & $4,111.20$ & $3,721.77$ & $3,494.61$ & $2,020.47$ & $1,874.12$ \\
\hline 2019 & $10,458.58$ & $8,616.45$ & $7,314.39$ & $6,393.77$ & $5,147.79$ & $4,765.86$ & $3,930.93$ & $3,557.31$ & $3,339.36$ & $2,003.06$ & $1,857.85$ \\
\hline 2020 & $10,125.00$ & $8,339.87$ & $7,078.10$ & $6,185.97$ & $4,908.08$ & $4,542.86$ & $3,750.65$ & $3,392.84$ & $3,184.11$ & $1,985.65$ & $1,841.58$ \\
\hline 2021 & $9,854.09$ & $8,115.27$ & $6,886.25$ & $6,017.28$ & $4,715.77$ & $4,363.97$ & $3,605.93$ & $3,260.82$ & $3,059.51$ & $1,977.24$ & $1,833.74$ \\
\hline 2022 & $9,583.17$ & $7,890.68$ & $6,694.40$ & $5,848.58$ & $4,523.45$ & $4,185.07$ & $3,461.20$ & $3,128.80$ & $2,934.90$ & $1,968.82$ & $1,825.91$ \\
\hline 2023 & $9,266.92$ & $7,628.48$ & $6,470.40$ & $5,651.60$ & $4,325.09$ & $4,000.55$ & $3,310.27$ & $2,991.12$ & $2,804.94$ & $1,965.61$ & $1,822.95$ \\
\hline 2024 & $8,950.66$ & $7,366.28$ & $6,246.41$ & $5,454.61$ & $4,126.72$ & $3,816.02$ & $3,159.34$ & $2,853.43$ & $2,674.98$ & $1,962.39$ & $1,820.00$ \\
\hline 2025 & $8,810.44$ & $7,250.11$ & $6,147.25$ & $5,367.47$ & $4,026.68$ & $3,723.00$ & $3,084.21$ & $2,784.94$ & $2,610.37$ & $1,961.67$ & $1,819.38$ \\
\hline 2026 & $8,670.21$ & $7,133.95$ & $6,048.09$ & $5,280.34$ & $3,926.65$ & $3,629.98$ & $3,009.09$ & $2,716.45$ & $2,545.75$ & $1,960.94$ & $1,818.75$ \\
\hline 2027 & $8,413.85$ & $6,921.44$ & $5,866.57$ & $5,120.73$ & $3,782.44$ & $3,495.85$ & $2,898.25$ & $2,615.37$ & $2,450.36$ & $1,960.92$ & $1,818.80$ \\
\hline 2028 & $8,157.50$ & $6,708.93$ & $5,685.05$ & $4,961.12$ & $3,638.23$ & $3,361.72$ & $2,787.41$ & $2,514.28$ & $2,354.96$ & $1,960.91$ & $1,818.85$ \\
\hline 2029 & $8,040.43$ & $6,611.97$ & $5,602.31$ & $4,888.43$ & $3,567.82$ & $3,296.26$ & $2,733.79$ & $2,465.42$ & 2,308.88 & $1,960.57$ & $1,818.59$ \\
\hline 2030 & $7,923.36$ & $6,515.01$ & $5,519.57$ & $4,815.75$ & $3,497.40$ & $3,230.81$ & $2,680.17$ & $2,416.56$ & $2,262.79$ & $1,960.23$ & $1,818.34$ \\
\hline
\end{tabular}




\section{Appendix C. Economic Potential Results}

Table C-1. Economic Potential Results by Turbine Class of Capital Cost Sensitivity Analysis in 2020 (MW)

\begin{tabular}{|c|c|c|c|c|c|}
\hline CAPEX (\$/W)/Turbine Class & $\begin{array}{l}\text { Residential } \\
(2-20 \mathrm{~kW})\end{array}$ & $\begin{array}{l}\text { Commercial } \\
(21-100 k W)\end{array}$ & $\begin{array}{l}\text { Midsize } \\
\text { (101-999kW) }\end{array}$ & $\begin{array}{l}\text { Large } \\
(>=1,000 \mathrm{~kW})\end{array}$ & Total \\
\hline 0 & $4,264.4$ & $3,975.6$ & $2,301.6$ & $1,955.9$ & $12,497.5$ \\
\hline 1 & $2,562.4$ & $2,606.7$ & $1,660.3$ & $1,546.8$ & $8,376.2$ \\
\hline 2 & $1,157.8$ & $1,260.4$ & 937.5 & $1,069.9$ & $4,425.6$ \\
\hline 3 & 397.2 & 424.6 & 655.3 & $1,069.9$ & $2,547.1$ \\
\hline 4 & 125.4 & 380.1 & 655.3 & $1,069.9$ & $2,230.7$ \\
\hline 5 & 40.2 & 380.1 & 655.3 & $1,069.9$ & $2,145.4$ \\
\hline 6 & 21.2 & 380.1 & 655.3 & $1,069.9$ & $2,126.5$ \\
\hline 7 & 20.0 & 380.1 & 655.3 & $1,069.9$ & $2,125.2$ \\
\hline
\end{tabular}

Table C-2. Economic Potential Results by Turbine Class of Capital Cost Sensitivity Analysis in 2030 (MW)

\begin{tabular}{|c|c|c|c|c|c|}
\hline CAPEX (\$/W)/Turbine Class & $\begin{array}{l}\text { Residential } \\
(2-20 \mathrm{~kW})\end{array}$ & $\begin{array}{l}\text { Commercial } \\
(21-100 \mathrm{~kW})\end{array}$ & $\begin{array}{l}\text { Midsize } \\
(101-999 k W)\end{array}$ & $\begin{array}{l}\text { Large } \\
(>=1,000 \mathrm{~kW})\end{array}$ & Total \\
\hline 0 & $2,234.3$ & $1,648.9$ & $1,131.8$ & 366.0 & $5,381.0$ \\
\hline 1 & $1,304.7$ & 775.9 & 495.4 & 152.2 & $2,728.2$ \\
\hline 2 & 685.2 & 509.8 & 266.0 & 101.9 & $1,563.0$ \\
\hline 3 & 470.4 & 509.8 & 266.0 & 101.9 & $1,348.1$ \\
\hline 4 & 448.6 & 509.8 & 266.0 & 101.9 & $1,326.4$ \\
\hline 5 & 448.6 & 509.8 & 266.0 & 101.9 & $1,326.4$ \\
\hline
\end{tabular}




\section{Appendix D. Value of Generation}

Table D-1. Value (\$) of 10,000 kWh of Generation by Technology by Year ${ }^{\mathrm{a}}$

\begin{tabular}{|c|c|c|c|c|c|c|c|}
\hline \multirow{2}{*}{ County } & \multirow{2}{*}{$\begin{array}{l}\text { Balancing } \\
\text { Authority }\end{array}$} & \multicolumn{2}{|c|}{2020} & \multicolumn{2}{|c|}{2025} & \multicolumn{2}{|c|}{2030} \\
\hline & & Wind & Solar & Wind & Solar & Wind & Solar \\
\hline Santa Barbara & CIPV & 298 & 327 & 350 & 339 & 348 & 325 \\
\hline Santa Clara & CIPV & 309 & 783 & 349 & 848 & 354 & 776 \\
\hline Inyo & CISC & 304 & 318 & 347 & 342 & 348 & 321 \\
\hline Yolo & CIPV & 289 & 185 & 331 & 200 & 331 & 174 \\
\hline Merced & CIPV & 290 & 300 & 335 & 299 & 337 & 274 \\
\hline Alameda & CIPV & 298 & 330 & 343 & 357 & 348 & 326 \\
\hline Napa & CIPV & 295 & 481 & 333 & 461 & 337 & 389 \\
\hline Santa Cruz & CIPV & 302 & 673 & 344 & 728 & 348 & 667 \\
\hline Imperial & IID & 296 & 304 & 329 & 328 & 325 & 302 \\
\hline Shasta & CIPV & 281 & 397 & 329 & 402 & 327 & 368 \\
\hline Calaveras & CIPV & 294 & 541 & 331 & 566 & 330 & 534 \\
\hline Del Norte & CIPV & 296 & 624 & 338 & 486 & 334 & 403 \\
\hline Mono & CISC & 319 & 369 & 360 & 417 & 357 & 376 \\
\hline Placer & CIPV & 294 & 371 & 338 & 386 & 334 & 353 \\
\hline San Diego & CISD & 324 & 505 & 367 & 539 & 363 & 506 \\
\hline Yuba & CIPV & 289 & 348 & 330 & 359 & 326 & 345 \\
\hline Siskiyou & CIPV & 299 & 710 & 348 & 845 & 346 & 685 \\
\hline San Luis Obispo & CIPV & 299 & 394 & 343 & 404 & 344 & 376 \\
\hline San Mateo & CIPV & 297 & 244 & 346 & 263 & 350 & 241 \\
\hline Marin & CIPV & 296 & 262 & 341 & 249 & 346 & 228 \\
\hline Modoc & CIPV & 301 & 447 & 355 & 502 & 356 & 456 \\
\hline Kings & CIPV & 265 & 398 & 304 & 439 & 306 & 402 \\
\hline Lake & CIPV & 282 & 737 & 320 & 559 & 326 & 806 \\
\hline Mendocino & CIPV & 291 & 357 & 333 & 378 & 333 & 352 \\
\hline Monterey & CIPV & 301 & 250 & 347 & 274 & 353 & 248 \\
\hline San Joaquin & CIPV & 290 & 200 & 332 & 225 & 335 & 206 \\
\hline Riverside & CISC & 306 & 282 & 348 & 288 & 347 & 272 \\
\hline Colusa & CIPV & 289 & 226 & 326 & 249 & 324 & 227 \\
\hline Sacramento & BANC & 308 & 244 & 347 & 255 & 344 & 208 \\
\hline Butte & CIPV & 286 & 280 & 326 & 331 & 326 & 283 \\
\hline Fresno & CIPV & 276 & 402 & 319 & 441 & 317 & 408 \\
\hline
\end{tabular}




\begin{tabular}{|c|c|c|c|c|c|c|c|}
\hline \multirow{2}{*}{ County } & \multirow{2}{*}{$\begin{array}{l}\text { Balancing } \\
\text { Authority }\end{array}$} & \multicolumn{2}{|c|}{2020} & \multicolumn{2}{|c|}{2025} & \multicolumn{2}{|c|}{2030} \\
\hline & & Wind & Solar & Wind & Solar & Wind & Solar \\
\hline Tulare & CISC & 292 & 786 & 335 & 835 & 335 & 790 \\
\hline Tehama & CIPV & 292 & 262 & 338 & 278 & 337 & 254 \\
\hline Nevada & CIPV & 282 & 484 & 323 & 485 & 320 & 444 \\
\hline Madera & CIPV & 281 & 513 & 325 & 560 & 325 & 522 \\
\hline Plumas & CIPV & 298 & 986 & 346 & 991 & 347 & 887 \\
\hline San Benito & CIPV & 309 & 538 & 349 & 581 & 355 & 532 \\
\hline Solano & CIPB & 285 & 126 & 327 & 140 & 331 & 128 \\
\hline Sonoma & CIPV & 295 & 328 & 338 & 377 & 342 & 324 \\
\hline Stanislaus & CIPV & 294 & 277 & 340 & 297 & 343 & 272 \\
\hline Contra Costa & CIPB & 291 & 297 & 334 & 319 & 340 & 292 \\
\hline Sutter & CIPV & 299 & 222 & 343 & 240 & 342 & 219 \\
\hline Trinity & CIPV & 277 & 1,716 & 317 & 1,953 & 314 & 1,775 \\
\hline Humboldt & CIPV & 291 & 489 & 334 & 556 & 332 & 444 \\
\hline El Dorado & CIPV & 296 & 554 & 335 & 581 & 331 & 553 \\
\hline Alpine & CIPV & 304 & 543 & 341 & 586 & 340 & 537 \\
\hline Amador & CIPV & 301 & 477 & 344 & 519 & 336 & 454 \\
\hline Glenn & CIPV & 297 & 243 & 336 & 261 & 333 & 238 \\
\hline Kern & CISC & 311 & 311 & 356 & 335 & 357 & 309 \\
\hline Lassen & CIPV & 300 & 530 & 347 & 588 & 352 & 540 \\
\hline Los Angeles & LDWP & 313 & 269 & 317 & 280 & 311 & 280 \\
\hline Orange & CISC & 330 & 407 & 372 & 439 & 371 & 412 \\
\hline San Bernardino & CISC & 308 & 263 & 347 & 268 & 346 & 251 \\
\hline San Francisco & CIPV & 296 & 137 & 342 & 148 & 348 & 136 \\
\hline Mariposa & CIPV & 287 & 840 & 326 & 959 & 327 & 906 \\
\hline Tuolumne & CIPV & 289 & 552 & 329 & 622 & 325 & 698 \\
\hline Ventura & CISC & 305 & 269 & 346 & 297 & 344 & 272 \\
\hline Sierra & CIPV & 292 & 806 & 337 & 694 & 339 & 615 \\
\hline
\end{tabular}

a These values were used to create Figure 15

BANC $=$ Balancing Authority of Northern California, CIPB $=$ Pacific Gas \& Electric Bay Area Balancing Authority, CIPV = Pacific Gas \& Electric Valley Area Balancing Authority, CISC = Southern California Edison Balancing Authority, LDWP = Los Angeles Department of Water \& Power, IID = Imperial Irrigation District 


\section{Appendix E. Change in Value of Generation}

Table E-1. Change in Value (\%) of 10,000 kWh of Generation by Technology by Year ${ }^{a}$

\begin{tabular}{|c|c|c|c|c|c|}
\hline \multirow[b]{2}{*}{ County } & \multirow[b]{2}{*}{$\begin{array}{l}\text { Balancing } \\
\text { Authority }\end{array}$} & \multicolumn{2}{|l|}{2025} & \multicolumn{2}{|l|}{2030} \\
\hline & & $\begin{array}{l}\text { Wind } \\
\text { Percentage } \\
\text { Change }\end{array}$ & $\begin{array}{l}\text { Solar } \\
\text { Percentage } \\
\text { Change }\end{array}$ & $\begin{array}{l}\text { Wind } \\
\text { Percentage } \\
\text { Change }\end{array}$ & $\begin{array}{l}\text { Solar } \\
\text { Percentage } \\
\text { Change }\end{array}$ \\
\hline Santa Barbara & CIPV & 117 & 104 & 117 & 99 \\
\hline Santa Clara & CIPV & 113 & 108 & 115 & 99 \\
\hline Inyo & CISC & 114 & 108 & 114 & 101 \\
\hline Yolo & CIPV & 115 & 108 & 115 & 94 \\
\hline Merced & CIPV & 116 & 100 & 116 & 91 \\
\hline Alameda & CIPV & 115 & 108 & 117 & 99 \\
\hline Napa & CIPV & 113 & 96 & 114 & 81 \\
\hline Santa Cruz & CIPV & 114 & 108 & 115 & 99 \\
\hline Imperial & IID & 111 & 108 & 110 & 99 \\
\hline Shasta & CIPV & 117 & 101 & 116 & 93 \\
\hline Calaveras & CIPV & 112 & 105 & 112 & 99 \\
\hline Del Norte & CIPV & 114 & 78 & 113 & 65 \\
\hline Mono & CISC & 113 & 113 & 112 & 102 \\
\hline Placer & CIPV & 115 & 104 & 114 & 95 \\
\hline San Diego & CISD & 113 & 107 & 112 & 100 \\
\hline Yuba & CIPV & 114 & 103 & 113 & 99 \\
\hline Siskiyou & CIPV & 116 & 119 & 116 & 97 \\
\hline San Luis Obispo & CIPV & 115 & 103 & 115 & 95 \\
\hline San Mateo & CIPV & 116 & 108 & 118 & 99 \\
\hline Marin & CIPV & 115 & 95 & 117 & 87 \\
\hline Modoc & CIPV & 118 & 112 & 118 & 102 \\
\hline Kings & CIPV & 115 & 110 & 115 & 101 \\
\hline Lake & CIPV & 114 & 76 & 115 & 109 \\
\hline Mendocino & CIPV & 115 & 106 & 115 & 99 \\
\hline Monterey & CIPV & 115 & 109 & 117 & 99 \\
\hline San Joaquin & CIPV & 115 & 112 & 116 & 103 \\
\hline Riverside & CISC & 114 & 102 & 114 & 96 \\
\hline Colusa & CIPV & 113 & 110 & 112 & 101 \\
\hline Sacramento & BANC & 113 & 105 & 112 & 85 \\
\hline Butte & CIPV & 114 & 118 & 114 & 101 \\
\hline
\end{tabular}




\begin{tabular}{|c|c|c|c|c|c|}
\hline \multirow[b]{2}{*}{ County } & \multirow[b]{2}{*}{$\begin{array}{l}\text { Balancing } \\
\text { Authority }\end{array}$} & \multicolumn{2}{|l|}{2025} & \multicolumn{2}{|l|}{2030} \\
\hline & & $\begin{array}{l}\text { Wind } \\
\text { Percentage } \\
\text { Change }\end{array}$ & $\begin{array}{l}\text { Solar } \\
\text { Percentage } \\
\text { Change }\end{array}$ & $\begin{array}{l}\text { Wind } \\
\text { Percentage } \\
\text { Change }\end{array}$ & $\begin{array}{l}\text { Solar } \\
\text { Percentage } \\
\text { Change }\end{array}$ \\
\hline Fresno & CIPV & 116 & 110 & 115 & 102 \\
\hline Tulare & CISC & 115 & 106 & 115 & 101 \\
\hline Tehama & CIPV & 115 & 106 & 115 & 97 \\
\hline Nevada & CIPV & 114 & 100 & 114 & 92 \\
\hline Madera & CIPV & 116 & 109 & 116 & 102 \\
\hline Plumas & CIPV & 116 & 101 & 116 & 90 \\
\hline San Benito & CIPV & 113 & 108 & 115 & 99 \\
\hline Solano & CIPB & 115 & 111 & 116 & 101 \\
\hline Sonoma & CIPV & 114 & 115 & 116 & 99 \\
\hline Stanislaus & CIPV & 116 & 107 & 117 & 98 \\
\hline Contra Costa & CIPB & 115 & 107 & 117 & 98 \\
\hline Sutter & CIPV & 115 & 108 & 114 & 99 \\
\hline Trinity & CIPV & 114 & 114 & 113 & 103 \\
\hline Humboldt & CIPV & 115 & 114 & 114 & 91 \\
\hline El Dorado & CIPV & 113 & 105 & 112 & 100 \\
\hline Alpine & CIPV & 112 & 108 & 112 & 99 \\
\hline Amador & CIPV & 114 & 109 & 112 & 95 \\
\hline Glenn & CIPV & 113 & 107 & 112 & 98 \\
\hline Kern & CISC & 114 & 108 & 115 & 99 \\
\hline Lassen & CIPV & 116 & 111 & 117 & 102 \\
\hline Los Angeles & LDWP & 101 & 104 & 99 & 104 \\
\hline Orange & CISC & 113 & 108 & 112 & 101 \\
\hline San Bernardino & CISC & 113 & 102 & 112 & 96 \\
\hline San Francisco & CIPV & 115 & 109 & 117 & 99 \\
\hline Mariposa & CIPV & 113 & 114 & 114 & 108 \\
\hline Tuolumne & CIPV & 114 & 113 & 113 & 126 \\
\hline Ventura & CISC & 114 & 110 & 113 & 101 \\
\hline Sierra & CIPV & 115 & 86 & 116 & 76 \\
\hline
\end{tabular}

a These values were used to create Figure 16.

BANC $=$ Balancing Authority of Northern California, CIPB $=$ Pacific Gas \& Electric Bay Area Balancing Authority, CIPV = Pacific Gas \& Electric Valley Area Balancing Authority, CISC $=$ Southern California Edison Balancing Authority, LDWP = Los Angeles Department of Water \& Power, IID = Imperial Irrigation District 